\title{
INTESTINAL BARRIER PHYSIOLOGY
}

\section{Genomic regulation of intestinal barrier functions with relation to lipid homeostasis.} Michael Müller.

Nutrition Metabolism and Genomics Group, Wageningen University, Dreijenplein 10, 6710 HB Wageningen, The Netherlands

The intestine as a gatekeeper plays a double-edge role in the uptake of dietary lipids. This is because absorption of dietary essential fatty acids and lipid micronutrients by the small intestine sustains human life, but at the same time, the efficient capacity of this organ to absorb our lipid-rich modern diet compromises and/or even harms people. Comprehensive detailed understanding of intestinal lipid homeostasis is therefore urgently needed. On a daily basis, the human small intestine metabolizes an average of $100 \mathrm{~g}$ of dietary fat, more than $90 \%$ of which is composed of triacylglycerols (TG). The absorption of lipids from the lumen is generally highly efficient, whereby approximately $4 \%$ of the ingested fat escapes into feces. Prior to absorption, TGs are hydrolyzed by gastric and pancreatic lipases to free fatty acids and 2-monoacylglycerols, both of which are taken up by enterocytes. We have comprehensively studied using microarrays and transgenic animals the effects of diets (rich in saturated and unsaturated fats) or pure fatty acids (in form of triglycerides) or of the PPAR $\alpha$ ligand WY and of fasting on genome wide effects on intestinal barrier functions with a focus on lipid signaling and homeostasis.

1) We examined the effects of a high-fat diet on expression and function of cholesterol transporters in the small intestine in mice. Npc111, Abca1, Abcg5, and Abcg8 were all downregulated after 2, 4, and 8 wk on a cholesterol-free, high-fat diet. This fatty acid-induced downregulation of cholesterol transporters is LXR $\alpha$ independent and associated with an induction of intestinal cholesterol biosynthesis as well as with a doubling of neutral fecal sterol loss. This shows induction of adaptive changes in small intestinal cholesterol metabolism during exposure to dietary fat.

2) The transcription factor PPAR $\alpha$ functions as an important nutrient sensor in mediating the effects of dietary fatty acids on intestinal gene transcription by regulating many genes involved in uptake of fatty acids, intracellular metabolism and chylomicron formation. We first demonstrated that PPAR $\alpha$ is highly expressed in villus cells of the duodenum and jejunum, coinciding with the primary anatomical location where fatty acids are digested, absorbed, and transported into the body as chylomicrons. Moreover, our genome wide analysis suggested that intestinal PPAR $\alpha$ controls these processes, among others.

3) We also identified intestinal barrier genes that were PPAR $\alpha$-dependently regulated after acute activation by fatty acids including sets of transporters and phase I/II metabolic enzymes involved in a) fatty acid oxidation, b) cholesterol, glucose, and amino acid transport and metabolism, c) intestinal motility, and d) oxidative stress defense. This knowledge provides a better understanding of the impact dietary fat has on the barrier function of the gut, identifies PPAR $\alpha$ as an important factor controlling this key function, and underscores the importance of PPAR $\alpha$ for nutrient-mediated gene regulation in intestine.

In conclusion, our studies demonstrate the great opportunities in using microarrays in genome wide studies of intestinal gene expression profiles to elucidate barrier gene regulation by dietary components in particular when transgenic mice are employed in such studies. 


\section{The desmosome-associated cellular prion protein contributes to the barrier function of the intestinal epithelium \\ Constance SV Petit ${ }^{\mathrm{a}}$, Frédérick Barreau ${ }^{\mathrm{b}}$, Béatrice Riveau ${ }^{\mathrm{a}}$, Danielle Château ${ }^{\mathrm{a}}$, Monique Rousset ${ }^{\mathrm{a}}$, Caroline \\ Clair $^{\mathrm{a}}$, Sophie Thenet ${ }^{\mathrm{a}, \mathrm{c}}$ \\ ${ }^{a}$ Centre de Recherche des Cordeliers, Equipe 4, UMRS 872, 75006 Paris, France., ${ }^{2}$ INSERM U843, Hôpital Robert Debré, 75019 Paris, \\ France. ${ }^{c}$ Ecole Pratique des Hautes Etudes, 75006 Paris, France.}

The intestinal function of barrier relies on epithelial cell polarization and on the integrity of their intercellular junctions. We previously described the localization of the ubiquitous cellular prion protein, $\operatorname{PrPc}$, at cell-cell junctions in enterocytes. Using Caco-2/TC7 enterocytes, we showed that PrPc is a partner of several desmosomal proteins and that its expression is necessary to address these proteins to intercellular junctions correctly. The aim of the present work was to characterize the physiological function of PrPc in the intestinal epithelium, and, more particularly, to determine if $\operatorname{PrPc}$ is involved in the intestinal function of barrier. Our results show that PrPc-deficient mice display an increased intestinal paracellular permeability for FITC-Dextran $4 \mathrm{kDa}$, both in vitro using Ussing chambers and in vivo after a bolus. Tight junctions are considered as key players regulating paracellular permeability. The analysis of their ultrastructure revealed an increase of their width in intestinal epithelial cells of PrPc-deficient mice. Defects in permeability and altered tight junctions being closely related to intestinal inflammation, we compared the susceptibility of PrPc-deficient and wild type mice to a DSS-induced experimental colitis. During the 6-day treatment with 3\% DSS, PrPc -/- mice showed a lower rate of survival and an accelerated body weight loss. Higher colitis disease activity indexes were scored in PrPc -/- throughout the DSS treatment and were accompanied by higher histological scores and increased rates of mucosal pro-inflammatory cytokines. Altogether, our results demonstrate for the first time that PrPc plays a role in the barrier function of the intestinal epithelium and in the susceptibility to inflammation. 


\section{Non Digestible Oligosaccharides open tight junctions in the enterocyte cell line, Caco-2}

Suha Althubaiti, John McLaughlin, Catherine O’Neill

Epithelial Sciences Research Group, School of Translational Medicine, University of Manchester, Manchester, UK

Introduction: non-digestible oligosaccharides (NDS) are part of the fibre component of the diet. In human intervention studies, NDS have been shown to impact positively on health in a several ways but the classical view of their actions is that they must be fermented by colonic bacteria to have any effects. NDS are not thought to interact directly with enterocytes. In this study we demonstrate that NDS open tight junctions in caco-2 cells and determine some of the molecular mechanisms involved. Methods: NDS including melibiose, lactulose and fruco-oligosaccharides were added to fully differentiated caco-2 cells growing on Transwell ${ }^{\mathrm{TM}}$ filters. Transepithelial electrical resistance (TEER) was measured using an EVOM (World precision instruments). Activation of protein kinase $\mathrm{C}$ was performed using high throughput fluorescence based assay (Imagen Biosciences ltd, UK). Tight junction proteins were analysed using western blotting. Results: within 1 hour of exposure to NDS we observed dose dependent decreases in the TEER of caco-2 cells which only occurred when NDS were added apically. The TEER continued to decrease up to 2 hours post treatment. NDS had differing effects on TEER but the largest decrease of around $60 \%$ occurred within 2 hours of treatment with $100 \mathrm{mM}$ melibiose ( $\mathrm{p}=0.02$ ). By contrast, $50 \mathrm{mM}$ sucrose, a digestible saccharide, had no effect on caco-2 TEER. Within 10 minutes of adding NDS, we observed mobilisation of protein kinase $\mathrm{C}$ and the protein kinase $\mathrm{C}$ inhibitor GF 109203X prevented the NDS-induced reductions in TEER. The myosin light chain kinase inhibitor, ML-7, also prevented NDS induced reduction in TEER by around $40 \%(\mathrm{p}=0.03)$. When cell extracts were analysed by western blotting, we observed an increase in the phosphorylation of myosin light chains in response to NDS. Conclusions: NDS can induce opening of tight junctions by a mechanism involving activation of protein kinase $\mathrm{C}$ and myosin light chain kinase. This suggests that caco-2 cells possess a receptive mechanism for NDS. 


\title{
Effect of sodium butyrate on barrier function of HT-29/B6/GR-MR cells in conjunction
} with down-regulation of claudin-2

\author{
Svenja Plöger ${ }^{\mathrm{a}}$, Theresa Bergann ${ }^{\mathrm{a}}$, Anja Fromm ${ }^{\mathrm{b}, \mathrm{c}}$, Roland Bücker ${ }^{\mathrm{c}}$, Michael Fromm ${ }^{\mathrm{b}}, \mathrm{Jörg}$ D. Schulzke ${ }^{\mathrm{a}, \mathrm{c}}$ \\ ${ }^{a}$ Department of Gastroenterology, Infectious Diseases and Rheumatology; ${ }^{b}$ Institute of Clinical Physiology; ${ }^{c}$ Department of General \\ Medicine, Campus Benjamin Franklin, Charité Berlin, Germany
}

Background and aims: The short chain fatty acid butyrate is known to have beneficial effects on colonocytes including preservation of barrier function or anti-inflammatory influences and plays also an important role in cell differentiation, apoptosis induction, and gene regulation by acting as a histone deacetylase (HDAC) inhibitor. Here, we aimed to characterize the barrier effect of butyrate via claudin-2.

Methods \& results: HT-29/B6/GR-MR cells were incubated with $2 \mathrm{mM}$ sodium butyrate. Transepithelial resistance increased to $176 \%$ after $24 \mathrm{~h}$ and to $246 \%$ after $48 \mathrm{~h}$. Quantitative immunoblot analyses revealed after $24 \mathrm{~h}$ a downregulation of claudin-2 protein level to $23 \%$. This result was confirmed in T84 and MDCK-C11 cells. Other barrier-relevant tight junction proteins like claudin-1, $-4,-5$, and -8 remained unchanged by butyrate. The HDAC inhibitor trichostatin A (TSA) had similar effects with a $39 \%$ decrease in claudin-2 expression, although not as intensive as butyrate. Real Time PCR analysis could confirm this result on mRNA level revealing 25 fold degradation of claudin- 2 mRNA to a fold-induction of 0.04 after sodium butyrate treatment. Neither changes in protein stability nor changes in mRNA stability did contribute to these changes. Electrophoretic mobility shift assays showed a reduced binding relation to a GATA binding-site within the claudin-2 promotor which points to transcriptional regulation by sodium butyrate being responsible for this effect.

Conclusions: Butyrate can decrease the transcription of claudin-2 resulting in an improved intestinal barrier function. This points to a substantial role of short chain fatty acids in innate immunity in interaction with the bacterial flora of the gut. 


\section{Yersinia enterocolitica induces barrier dysfunction in HT-29/B6 cells by causing discrete "leaky regions" exhibiting tight junction alterations}

Nina A Hering ${ }^{\mathrm{a}}$, Jan F Richter ${ }^{\mathrm{b}}$, Susanne M Krug ${ }^{\mathrm{b}}$, Dorothee Günzel ${ }^{\mathrm{b}}$, Anja Fromm ${ }^{\mathrm{a}, \mathrm{b}}$, Erwin Bohn ${ }^{\mathrm{d}}$, Rita Rosenthal $^{\mathrm{b}}$, Roland Bücker ${ }^{\mathrm{a}}$, Michael Fromm ${ }^{\mathrm{b}}$, Hanno Troeger ${ }^{\mathrm{c}}$, Jörg D Schulzke ${ }^{\mathrm{a}, \mathrm{c}}$

${ }^{a}$ Dept. of General Medicine; ${ }^{b}$ Inst. of Clinical Physiology; ${ }^{c}$ Dept. of Gastroenterology, Infectious Diseases and Rheumatology, Campus Benjamin Franklin, Charité Berlin; ${ }^{d}$ Inst. of Medical Microbiology and Hygiene, University Tübingen, Germany

Yersinia enterocolitica is a common cause of acute gastroenteritis. In order to clarify the mechanisms leading to barrier dysfunction and diarrhea we studied the pathomechanisms of this infection in detail. Exposure of human colonic HT-29/B6 monolayers to Y. enterocolitica resulted in a decrease in paracellular resistance from $3012 \pm 496$ to $354 \pm 100 \Omega \cdot \mathrm{cm}^{2}$. In parallel, permeabilities to mannitol (182 Da) and to fluorescein (332 Da) were increased, while $\mathrm{I}_{\mathrm{SC}}$ did not change. This effect was time-dependent, required the presence of living bacteria, and could not be triggered by bacterial supernatants. Concomitantly, Y. enterocolitica induced necrosis as indicated by an increased LDH-release, while epithelial apoptosis was not upregulated. Local changes in ion conductivity were detected by conductance scanning, indicating "leaky regions" within the epithelium which were visualized by biotinylation and confocal microscopy. In these regions the tight junction proteins claudin-3, -4 and -8 were redistributed into the cytoplasma. In addition, the expression of claudin-2, $-3,-8$ and -10 as well as ZO-1 was diminished as quantified by immunoblotting. Moreover we found claudin- 8 to be regulated via the c-Jun N-terminal kinase, the inhibition of which partially prevented the $Y$. enterocolitica-induced decrease in transepithelial resistance and restored claudin-8 protein level. In conclusion, barrier dysfunction in $Y$. enterocolitica infection occurs in a patchy distribution of circumscribed barrier defects as result of a tight junction protein down-regulation and re-distribution and in response to induction of necrosis. As a consequence, leak flux diarrhoea and antigen-uptake provoking extraintestinal arthritis may be triggered. 


\title{
Aerolysin, a pore-forming toxin of Aeromonas hydrophila, disturbs tight junction integrity and wound healing
}

\author{
Roland Bücker ${ }^{\mathrm{a}}$, Susanne M Krug ${ }^{\mathrm{b}}$, Rita Rosenthal ${ }^{\mathrm{b}}$, Dorothee Günzel ${ }^{\mathrm{b}}$, Michael Fromm ${ }^{\mathrm{b}}$, Trinad Chakraborty ${ }^{\mathrm{d}}$, \\ Hans-Jörg Epple ${ }^{\mathrm{c}}$, Jörg-Dieter Schulzke ${ }^{\mathrm{a}, \mathrm{c}}$ \\ ${ }^{a}$ Dept. General Medicine; ${ }^{b}$ Inst. Clinical Physiology; ${ }^{c}$ Dept. Gastroenterology, Charité Berlin; ${ }^{d}$ Dept. Medical Microbiology and Virology, \\ University Giessen, Germany
}

Introduction. Aeromonas hydrophila causes gastroenteritis, septicaemia, and necrotising soft tissue wound infections. Although the pathogenesis of A. hydrophila and its enterotoxin/haemolysin aerolysin has been well described, the mechanisms of the epithelial barrier dysfunction and necrotisation are not completely understood.

Methods. Human colon HT-29/B6 monolayers were apically inoculated with isolates of A. hydrophila or by the secreted toxin aerolysin. Transepithelial resistances and macromolecule fluxes were determined in Ussing chambers. Paracellular and transcellular resistance were measured by two-path impedance spectroscopy (2PI). The subcellular distribution of tight junction (TJ) and cytoskeleton proteins was analyzed by confocal microscopy. The ability of wound healing was quantified in infected epithelial cells by induction of single cell lesions and measuring of recovery time.

Results. The main paracellular part of epithelial dysfunction had not been considered so far, since aerolysin has only been known to induce active chloride secretion. Here, we show that infection of HT-29/B6 cells more than doubled paracellular permeability to fluorescein and to 4-kDa-dextran. In parallel, 2PI measurements revealed a rapid and permanent decrease in paracellular resistance with either A. hydrophila supernatants or aerolysin only. As structural correlate, TJ proteins were redistributed off the TJ by actomyosin contraction via intracellular calcium signalling. Moreover, we measured a defective epithelial wound closure through disturbance of cytoskeletal and TJ components. All effects could be prevented by pre-treatment with zinc, which inhibits aerolysin pore formation in the host cell membrane. The inhibition by zinc parallels the efficacy of zinc therapy of epithelial lesions and diarrhoea.

Conclusion. Aerolysin induces epithelial barrier dysfunction along the paracellular route via TJ disruption (leak flux) and concomitantly disturbs wound closure as an early event during infection and thus contributes to our understanding of the pathomechanisms of haemolysin-producing bacteria. 


\title{
Absorption enhancers and jejunal uptake kinetics in vitro of methyl $\alpha$-D-glucoside
}

\author{
Katja Eberhardt ${ }^{\mathrm{a}}$, Klaus Schümann ${ }^{\mathrm{b}}$, Bernd Elsenhans ${ }^{\mathrm{a}}$ \\ ${ }^{a}$ Walther-Straub Institute of Pharmacology and Toxicology, Ludwig Maximilians Universität München, Germany Nußbaumstrasse 26, D- \\ 80336 München, ${ }^{b}$ Research Center of Nutrition and Food Sciences, Biochemistry Unit, Technische Universität München, Germany
}

So-called absorption enhancers (AEs) are proposed to increase small-intestinal absorption of poorly available drugs. While some of them inhibit the mucosal metabolism or active efflux of drugs, others increase drug permeability by impairing mucosal barrier function. Thus, this latter type of AE, e.g., deoxycholate (DOC), polyethyleneimine (PEI), decanoate (DEC), and ethylenediamminetetraacetate (EDTA) may impair sodiumdependent active transport proccesses, due to their different structures and properties not necessarily by the same mechanism, however. Therefore, these AEs were compared for their effect on the kinetic parameters of intestinal methyl $\alpha$-D- $\left[{ }^{14} \mathrm{C}\right]$ glucoside uptake. $\mathrm{K}_{\mathrm{M}}$ and $\mathrm{V}_{\max }$ were determined in vitro by means of 5 -min incubations with everted rings of rat jejunum and by analysing the concentration-dependent tissue uptake according to Lineweaver-Burk (for results see Table).

\begin{tabular}{cccccc}
\hline & control & DOC & PEI & DEC & EDTA \\
\hline $\mathrm{K}_{\mathrm{M}}(\mathrm{mmol} / \mathrm{l})$ & $4.8 \pm 0.9$ & $6.9 \pm 1.2^{*}$ & $6.6 \pm 0.9^{*}$ & $4.5 \pm 0.5$ & $4.7 \pm 0.5$ \\
$\mathrm{~V}_{\max }(\mathrm{mmol} / \mathrm{l} / \mathrm{min})$ & $11.3 \pm 2.3$ & $8.2 \pm 1.0^{*}$ & $8.0 \pm 1.2^{*}$ & $6.3 \pm 0.4^{*}$ & $7.0 \pm 0.8^{*}$ \\
\hline \multicolumn{5}{c}{$\mathrm{M} \pm \mathrm{SD}, \mathrm{N}=6 ;{ }^{*} \mathrm{p}<0.05$ (ANOVA) } \\
\hline
\end{tabular}

While all AEs employed reduced the maximal uptake capacity $\left(\mathrm{V}_{\max }\right)$ of the jejunal mucosa as compared to the control, only DOC and PEI increased $\mathrm{K}_{\mathrm{M}}$, i.e., reduced the affinity of the glucose analogue for its transport carrier. Since unstirred water layers are unlikely to be changed under the present conditions, membrane interactions are considered to be responsible for the $\mathrm{K}_{\mathrm{M}}$ effect, yet the mode of action of the lipophilic DOC may differ from that of the hydrophilic PEI. 


\title{
Comparison of tight junction barrier properties with expression of claudins along rat
} intestine

\author{
Alexander G Markov ${ }^{\mathrm{a}}$, Anna Veshnyakova ${ }^{\mathrm{b}}$, Michael Fromm ${ }^{\mathrm{c}}$, Maren Amasheh ${ }^{\mathrm{d}}$, Salah Amasheh ${ }^{\mathrm{c}}$ \\ ${ }^{a}$ University of St. Petersburg, St. Petersburg, Russia; ${ }^{b}$ Leibniz Institute of Molecular Pharmacology, Berlin, Germany; Institute of Clinical \\ Physiology and ${ }^{d}$ Department of Gastroenterology, Charite, Campus Benjamin Franklin, Berlin, Germany
}

The tight junction (TJ) protein family of claudins is regarded to determine barrier properties in a wide variety of epithelia. Aim of the study was to compare epithelial barrier properties directly with the presence of TJ proteins in exactly defined segments along rat intestine.

Epithelial resistance $\left(\mathrm{R}^{\mathrm{epi}}\right)$ of duodenum, jejunum, ileum, and colon tissue preparations were measured and discriminated from subepithelial resistance by impedance spectroscopy. In parallel, expression of TJ proteins was analyzed by Western blots and immune fluorescence confocal microscopy.

$\mathrm{R}^{\text {epi }}$ was $40.8 \pm 3.6,28.2 \pm 6.2,22.8 \pm 3.3$, and $124.3 \pm 4.3 \Omega \cdot \mathrm{cm}^{2}$ in duodenum, jejunum, ileum, and colon, respectively. Thus, colon was characterized by higher $\mathrm{R}^{\mathrm{epi}}$ than more proximal segments. However, among the small intestinal segments, $\mathrm{R}^{\mathrm{epi}}$ was highest in duodenum and lowest in ileum. Along the intestine, claudins -1 , $-2,-3,-4,-5,-7,-8$, and -12 were detected by Western blotting with different signal intensities. In accordance with $\mathrm{R}^{\mathrm{epi}}$, colon showed strongest signals for tightening claudins $-1,-3,-4,-5$, and -8 . The paracellular channel claudin-2 showed strongest signals in ileum, and jejunum revealed strongest signals for claudin-12, but no signals for claudin-4 and -8 . Duodenum showed weakest expression of pore-forming claudin-2, and strongest signals for tightening claudins $-3,-4,-5$, and -8 , compared to jejunum and ileum.

Along the intestine, claudins show a marked segment-specific expression which is in accordance with respective barrier properties. Aside from the maximum expression of tightening TJ proteins in the tight colonic surface epithelium, the correlation of structure and function of the TJ along the gut axis highlights the specific role of the duodenal barrier as the first segment facing the acidic gastric content. 


\section{CD97 attenuates colitis and strengthens intestinal adherens junctions by stabilization of membrane-bound $\beta$-catenin \\ Gabriela Aust ${ }^{\mathrm{a}}$, Susann Becker ${ }^{\mathrm{a}}$, Manja Wobus ${ }^{\mathrm{a}}$, Rick Schneider ${ }^{\mathrm{a}}$, Salah Amasheh ${ }^{\mathrm{c}}$, Doreen Sittig ${ }^{\mathrm{a}}$, Christiane Kerner $^{\mathrm{a}}$, Ronald Naumann ${ }^{\mathrm{d}}$, Jörg Hamann ${ }^{\mathrm{e}}$, Elke Wandel ${ }^{\mathrm{ab}}$ \\ ${ }^{a}$ Department of Surgery, Research Laboratories, ${ }^{b}$ Translational Centre for Regenerative Medicine, University of Leipzig, ${ }^{c}$ Institute of Clinical Physiology, Charité, Berlin, 'Transgenic Core Facility, MPI for Molecular Cell Biology and Genetics, Dresden, Germany; ${ }^{e}$ Department of Experimental Immunology, Academic Medical Center, University of Amsterdam, The Netherlands}

E-cadherin-based adherens junctions contribute crucially to the organization and stabilization of the polarized intestinal cell layer. Here, we demonstrate that the adhesion G-protein-coupled receptor CD97 is preferentially present in these junctions of human colonic enterocytes. To investigate the function of CD97 transgenic Tg(villin-CD97) mice overexpressing CD97 in intestinal epithelial cells were generated and subjected to dextran sodium sulfate (DSS)-induced colitis. We found a CD97 cDNA copy number-dependent reduction of DSS-induced colitis in Tg compared to wild-type (WT) mice. Ultrastructural analysis revealed that overexpression of CD97 strengthened lateral cell-cell contacts between enterocytes, which, in contrast, were weakened in CD97 knockout (Ko) mice. Transepithelial resistance was not altered in Tg and Ko mice, indicating that tight junctions were not affected. CD97 overexpression increased several plaque core proteins as b-catenin anchoring the receptor E-cadherin to the actin cytoskeleton in adherens junctions. CD97 upregulated membranebound but not cytoplasmic or nuclear $\beta$-catenin. In parallel, CD97 reduced phospho- $\beta$-catenin, labeled for degradation, thus stabilizing non-phospho $\beta$-catenin. Glycogen synthase kinase-3b (GSK-3b), normally phosphorylating $\beta$-catenin, was inhibited by activation of Akt. In summary, CD97 increases the structural integrity of enterocytic adherens junctions by increasing and stabilizing junctional $\beta$-catenin, thereby regulating intestinal epithelial strength and attenuating experimental colitis. 


\section{Functional regulation of tight junction proteins claudins 3 and 5 by shear stress and hypoxia}

Susanne Milatz ${ }^{\mathrm{a}}$, Andreas Zakrzewicz ${ }^{\mathrm{b}}$, Johannes Wolschner ${ }^{\mathrm{a}}$, Michael Fromm ${ }^{\mathrm{a}}$, Salah Amasheh ${ }^{\mathrm{a}}$

${ }^{a}$ Dept. of Clinical Physiology, ${ }^{b}$ Dept. of Physiology, Campus Benjamin Franklin, Charité Berlin, Germany

Claudin-3 and claudin-5 are present in intestinal epithelia as well as in endothelia. For characterizing these two tight junction proteins we performed overexpression studies in model epithelial cells, MDCK II and Caco-2, and regulation studies in model endothelial cells, HUVEC. A novel MDCK II clone was generated exhibiting low genuine claudin-2 expression. Here, overexpression of human claudin-3 caused an increase in paracellular resistance which was based on equal alterations of $\mathrm{Na}^{+}$and $\mathrm{Cl}^{-}$permeabilities. The permeability to water was unchanged. For claudin-5 we have shown recently that it is genuinely expressed in HT-29/B6 cells. Overexpression of claudin-5 in Caco-2 cells, which lack claudin-2, caused an increase in resistance and a decrease in mannitol permeability. To study the regulation of these claudins, the expression of tight junction proteins was analyzed in human umbilical vein endothelial cells (HUVEC) and the effects of wall shear stress and of hypoxia were measured. Monolayers were exposed for $24 \mathrm{~h}$ to a physiological shear stress of $6 \mathrm{dyn} / \mathrm{cm}^{2}$ or to zero shear stress as occurring after obliteration. Zero shear stress led to an upregulation of occludin, claudin-3, claudin-5, and also claudin-11, but not claudin-23 or b-actin. Upregulation of all proteins was due to increased mRNA levels. Inhibitor studies revealed an involvement of the PI3 kinase pathway. Combined treatment with zero shear stress and hypoxia resulted in drastically increased claudin-3 expression. We demonstrate that claudin-3 and -5 are distinct barrier builders in epithelia and are regulated in a model endothelium by shear stress and oxygen saturation. Increased expression of claudin-3 and -5 under zero shear stress and under hypoxic conditions would limit the passage of solutes from the blood into the surrounding tissue after stasis of blood flow. 


\section{Effects of PPARs on tight junction structure and function in Caco-2 cells}

Lynn Cotterill, Bill Newman, Catherine O’Neill

Epithelial Sciences Research Group, School of Translational Medicine, University of Manchester, Manchester, UK

Introduction: The peroxisome proliferator-activated receptors (PPARs) are ligand-activated transcription factors that regulate the expression of several genes involved in diverse processes such as cellular differentiation, development and metabolism. Three PPAR isotypes have been identified: PPAR- $\alpha, \gamma$ and $\beta / \delta$. The subtypes are similar in structural homology yet have differential effects and expression patterns. In this study, we investigated the effects of PPAR agonists and antagonists on the development of the caco-2 cell tight junction.

Methods: PPAR agonists or antagonists were added to caco-2 cells growing on Transwell ${ }^{\mathrm{TM}}$ filters. Transepithelial resistance (TEER) was measured with time using an EVOM (WPI UK). Tight junction proteins were analysed using immunoblotting. Results: The TEER of caco-2 cells rises over time in culture to a

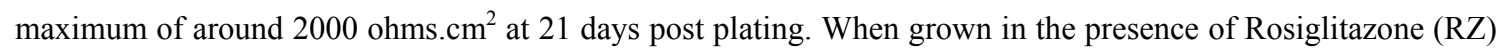
or GW9662, (PPAR $\gamma$ agonist and antagonist respectively), no difference between TEER at 21 days in control and treated cells was observed. However, in the presence of Troglitazone (TRO), which has PPAR $\alpha$ and $\gamma$ activating ability, an approximately $30 \%$ increase in the TEER at 21 days was observed $(\mathrm{p}=0.03)$. By contrast, GW6471, a PPAR $\alpha$ antagonist caused a reduction in TEER of $45 \%$ compared with control cells. No difference in the expression of the tight junction proteins claudins 1,3 or 4 was observed in cells treated with either RZ or GW9662. However, in TRO treated cells, the expression of claudin 3 and 4 appeared to be increased $\sim 2.2$ and 1.6 fold respectively. No change was observed in claudin 1 expression. 


\title{
NEUROENDOCRINE REGULATION
}

\section{Enteroendocrine cell function in intestinal inflammation}

\author{
Gordon Moran, John McLaughlin
}

School of Translational Medicine, Stopford Building, University of Manchester, Manchester, M13 9PL

Background: Appetite is often impaired in patients with gastrointestinal inflammation, but the precise biological basis for this is extremely unclear. Gastrointestinal satiety signals are produced by enteroendocrine cells (EEC), and signal through endocrine and paracrine pathways to regulate food intake. Amongst other hormones, polypeptide YY (PYY) and glucagon like peptide-1 (GLP-1) possess satiety-inducing properties. Recent animal research has suggested that immune regulated upregulation of EEC activity plays a mechanistic role in the appetite and feeding disturbance observed during gut inflammation. This is a discovery that now requires clinical translation.

Methodology: Patients with small intestinal Crohn's disease (CD) were studied, with active small and large bowel inflammation (SB and LB respectively), and age/sex matched controls. Gut peptide responses to a mixed nutrient test meal were studied using a multiplex-ELISA technique. Patient symptoms were assessed using a validated visual analogue score (VAS).

Results: CD patients displayed a significant reduction in appetite by VAS $(\mathrm{p}<0.0001)$. Total PYY was increased 2.15-fold in SB CD ( $\mathrm{p}=0.04)$ but not LB CD. A significant correlation was observed between postprandial PYY responses and symptoms, specifically nausea and bloatedness ( $\mathrm{p}=0.009 \& 0.03$ respectively). The postprandial rise in active GLP-1 in the SB CD group was more sustained when compared to controls $(\mathrm{p}=0.01)$. Ghrelin was 3-fold higher in the CD group compared to controls and showed reversed responsiveness by rising postprandially. This correlated with the Crohn's disease activity index $(\mathrm{p}=0.02)$. Leptin showed no correlation to intestinal inflammation but showed significant correlation with the body mass index and a negative correlation with weight loss $(\mathrm{p}=0.0001 \& \mathrm{p}=0.01$ respectively).

Discussion: These results are compatible with a potential role of EEC in appetite dysregulation in intestinal inflammation. Enhanced EEC responses may directly and adversely affect appetite in such patients through increased gut-brain signaling after eating. The potential impact on nutrient handling and transport also requires study. 


\title{
Intestinal epithelial stem/progenitor cells are controlled by mucosal afferent nerves
}

\author{
Ove Lundgren $^{\mathrm{a}}$, Mats Jodal ${ }^{\mathrm{a}}$, Lennart Svensson ${ }^{\mathrm{b}}$ \\ ${ }^{a}$ Neuroscience and Physiology, Gothenburg University, Goteborg, Sweden. ${ }^{b}$ Department of Molecular Virology, Linkoping University, \\ Linkoping, Sweden.
}

The intestinal epithelium, the most rapidly self-renewing epithelium in adult mammals, represents an outer surface to the organism exposed to luminal contents of widely varying composition. The maintenance of the epithelium is of great importance for the survival of the organism, since chemicals and/or microorganisms, if allowed to pass the epithelial barrier, may represent a deadly threat. Thus, the intestinal epithelium may be looked upon as being an important part of innate immunity. The key cells in this event are the intestinal stem and progenitor cells located to the intestinal crypts. We have studied if there is a nervous control of stem/progenitor cell renewal of the small intestine. Mucosal thin afferent nerves were stimulated by exposing the intestinal mucosa to capsaicin (the "hot" agent of red pepper) which increased mucosal thymidine kinase (TK) activity (exclusively associated with DNA synthesis and growth), thymidine incorporation into DNA, and number of crypt cells labelled with BrdU (a thymidine analogue), reflecting an augmented epithelial cell renewal. The increased TK activity and thymidine incorporation into DNA was nervously mediated to judge from the inhibitory effects of exposing the mucosa to lidocaine (a local anesthetics) or by giving four different neurotransmitter (muscarinic, nicotinic, substance P (SP) and calcitonin gene related peptide (CGRP)) receptor antagonists i.v.. Intra-arterial infusion of SP or CGRP increased intestinal TK activity, effects that were not seen after muscarinic receptor blockade. After degeneration of the intestinal external nerves capsaicin did not increase TK activity, indicating that the nervous control is exerted by a so called axon reflex. We propose that the intestinal stem/progenitor cells are controlled by a cholinergic neuron, which, in turn, is under the influence of mucosal afferent neuron(s) releasing acetylcholine and/or SP and/or CGRP via an axon reflex. Furthermore, in mice lacking the capsaicin receptor, thymidine incorporation into DNA and number of crypt cells labeled with BrdU was lower than in wild type animals implying that nerves are important for the stem cell niche also in the absence of luminal capsaicin, a conclusion also supported by the observation that muscarinic receptor blockade lowers thymidine incorporation into DNA by $60 \%$ in intestinal control segments (no capsaicin). We conclude that nerves play an important role in maintaining the intestinal epithelial barrier. 


\section{Mechanism of bradykinin $B_{2}$ receptor mediated action at submucosal ganglia from rat} distal colon

Martin Diener, Janine Avemary

Institute for Veterinary Physiology, Justus-Liebig-University Giessen, Germany

Bradykinin acts as inflammatory mediator in the gut. In the present study we characterized bradykinininduced changes in the intracellular $\mathrm{Ca}^{2+}$ concentration $\left(\left[\mathrm{Ca}^{2+}\right]_{\mathrm{i}}\right)$ in whole mount submucosal preparations and membrane potential of cultured submucosal neurones from rat distal colon. Bradykinin $\left(2 \cdot 10^{-10}-2 \cdot 10^{-7} \mathrm{~mol} / \mathrm{l}\right)$ evoked a concentration-dependent increase in $\left[\mathrm{Ca}^{2+}\right]_{\mathrm{i}}$ in about $90 \%$ of the investigated neurones. This $\mathrm{Ca}^{2+}$ response was abolished by the bradykinin $\mathrm{B}_{2}$ receptor antagonist $\mathrm{HOE} 140$. The $\mathrm{B}_{2}$ receptor agonist $\left[\mathrm{Hyp}^{3}\right]$ bradykinin mimicked the kinin response. Immunohistochemical experiments confirmed the presence of bradykinin $B_{2}$ receptors in submucosal neurones. Blocking of $G_{q / 11}$ proteins with YM-254890 suppressed the action of bradykinin, revealing that neuronal bradykinin $\mathrm{B}_{2}$ receptors are coupled to this $\mathrm{G}$ protein. However, the subsequent signalling cascade differed from the classical phospholipase $\mathrm{C}$ signalling pathway, as the bradykinin response was resistant against the phospholipase C inhibitor U-73221, the ryanodine receptor antagonist dehydroryanodine, and only marginally sensitive against the blocker of $\mathrm{IP}_{3}$-receptors xestospongin $\mathrm{C}$. Vice versa, the effect of bradykinin was nearly completely dependent on the presence of external $\mathrm{Ca}^{2+}$ and could be inhibited by blockers of L-, N- and Q-subtypes of $\mathrm{Ca}_{\mathrm{v}}$ channels, suggesting that the bradykinin-induced $\mathrm{Ca}^{2+}$ response is mediated by an influx from the extracellular space via $\mathrm{Ca}_{\mathrm{v}}$ channels. These channels are probably activated by a membrane depolarization, which was confirmed by patch-clamp experiments at cultured neurones, where bradykinin induced a depolarization of the membrane of about $14 \mathrm{mV}$, presumably by inhibition of a $\mathrm{K}^{+}$ conductance. These results suggest a direct interaction of a $\mathrm{G}_{\mathrm{q} / 11}$ protein with $\mathrm{K}^{+}$channels in rat submucosal neurones. 


\section{Influence of carbon monoxide on anion secretion in rat colon}

Julia Steidle, Martin Diener

Institute for Veterinary Physiology, Justus-Liebig-University Giessen, Germany

Carbon monoxide $(\mathrm{CO})$ is known as a respiratory gaseous toxin, which is produced in tissues during the degradation of hemoglobin. Recently it has been shown that $\mathrm{CO}$ is a physiological vasodilator in blood circulation and a gasotransmitter engaged in the regulation of several cell functions. As enteric neurons, the key players in the regulation of intestinal transport, express the enzymes for $\mathrm{CO}$ production, the aim of the present study was to investigate whether carbon monoxide induces changes in ion transport and to study the mechanisms involved. Mucosa-submucosa-preparations of the rat colon were voltage-clamped in an Ussing-chamber. In these preparations, tricarbonyldichlororuthenium(II) dimer (RuCO), a CO-donor, evoked a concentration-dependent increase in short-circuit current (Isc). The effect showed a strong segment-dependency, i.e. it was more pronounced in the distal compared to the proximal colon. Repeated application of RuCO resulted in a desensitization of the tissue. Anion substitution experiments suggest that a secretion of chloride and bicarbonate underlye the RuCO-induced current. This is supported by transport inhibitor experiments, where glibenclamide, a blocker of the apical CFTR-channel, and bumetanide, a blocker of the basolateral $\mathrm{Na}^{+}-\mathrm{K}^{+}-2 \mathrm{Cl}^{-}$-transporter, inhibited the Isc induced by the $\mathrm{CO}$ donor. Membrane permeabilisation indicate an involvement of basolateral $\mathrm{K}^{+}$and apical $\mathrm{Ca}^{2+}$-dependent $\mathrm{Cl}^{-}$channels. A partial inhibition by the neurotoxin, tetrodotoxin, suggests the involvement of secretomotor neurons in this response. Imaging experiments with fura-2 revealed an increase of the cytosolic $\mathrm{Ca}^{2+}$-concentration induced by $\mathrm{CO}$. This increase depends on the influx of extracellular $\mathrm{Ca}^{2+}$ but not on a release of $\mathrm{Ca}^{2+}$ from intracellular stores. In immunhistochemical investigations the existence of both enzymes for CO production, hemoxygenase I and II, were demonstrated. So there could be the possibility of endogeneous carbon monoxide production. These results should be approved by RT-PCR. Further experiments shall clarify, if there is a colocalisation of hemoxygenases and nitric oxide synthases in colonic tissue. 


\section{Distribution of circadian rhythms along rat colonic crypts}

Matúš Soták ${ }^{\mathrm{a}}$, Lenka Polidarováb, Alena Sumováb, Jiří Pácha ${ }^{\mathrm{a}}$.

${ }^{\mathrm{a}}$ Department of Epithelial Physiology, ${ }^{b}$ Department of Neurohumoral Regulations, Institute of Physiology, Academy of Sciences of the Czech Republic, Prague, Czech Republic.

Introduction: Organisms living in rhythmically changing environment possess timing machine based on molecular clocks in both the central nervous system and peripheral tissues including liver and alimentary tract where the clock genes exhibit rhythmic expression. The circadian clock regulates hundreds of functions including proliferation and intestinal digestion and absorption. We have shown recently in intestinal epithelium the rhythmic expression of $\mathrm{Na}(+) / \mathrm{H}(+)$ antiporter $N h e 3$ and the cell cycle regulator $W e e l$, which are suggested to be clock-controlled genes. Moreover, we have demonstrated rhythmic expression of another ion transporter $\mathrm{Dra}$ and g subunit of the sodium channel ENaC.

Aim: As these studies showed rhythms in scrapped mucosa from a large area of colonic epithelia, the goal of this study was therefore to elucidate whether there are differences in the distribution and phase shift of circadian clock and rhythms along the base-to-surface axis of colonic crypts.

Methods: Adult male Wistar rats were kept in light-dark regime LD 12:12. Sample collection was provided every 4 hours during 24 hours, colonic tissue was snap-frozen and histological sections were prepared using cryostat. Laser capture microdissection was used for specific tissue collection of crypt base and mouth, respectively. Total RNA was isolated and examined by quantitative real-time RT-PCR.

Results: We demonstrated the functional intestinal circadian clock- (rhythmic expression of clock genes mRNA) in both crypt base and mouth with exactly the same phase of rhythm along the crypt axis. Furthermore we found rhythmic expression of the cell cycle regulator Weel mRNA in both crypt base and mouth and rhythmic expression of $\mathrm{g} E \mathrm{NaC}$ and Nhe3 mRNA in apical part of crypts.

Conclusion: We determined phase-synchronized expression of clock genes and clock-controlled genes in basal vs. apical part of colonic crypts. The data demonstrate for the first time the functional synchronization of clocks in particular crypts.

Supported by grants from the Ministry of Health no. NS 9982-4 and the Academy of Sciences no. AV0Z50110509. 


\title{
Epithelial secretion of the porcine proximal colon is stimulated by submucous
} neurotransmitters

\author{
Anja Mauksch, Gotthold Gäbel, Helga Pfannkuche \\ Institute of Veterinary-Physiology, Leipzig University, Germany
}

Various epithelial functions in the gastrointestinal tract are controlled by neurotransmitters of the enteric nervous system. Since secretory diarrhea is a common problem in pigs, we focused on the pro- and antisecretory actions of neurotransmitters derived from submucous neurones of the porcine proximal colon. The presence of the putative neurotransmitters was shown by indirect immunofluorescence staining of cryostat sections. Antibodies against the following antigens were used, choline-acetyltransferase (ChAT), nitric oxide synthase (NOS), substance P (SP), vasoactive intestinal peptide (VIP), neuropeptide Y (NPY) and somatostatin (SOM). All off these neurotransmitters were found in fibres and neuronal somata of the submucous plexus. A strong expression on nerve fibres projecting into the epithelial layers was seen for VIP, NPY and SP. Expression of ChAT was not only found on neuronal structures but also within the enterocytes. To evaluate whether these neurotransmitters were able to stimulate or inhibit epithelial secretion, mucosa-submucosa preparations were mounted in Ussing chambers under short circuit conditions. Increase in short circuit current (Isc) was taken for epithelial electrogenic secretion. Serosal application of carbachol (CA, cholinergic agonist), sodium nitroprussid (NO donor), SP or VIP induced a significant increase in Isc. Preincubation with tetrodotoxin (TTX) or indomethacin (IM) did not alter the effect of CA, NO or VIP. In contrast, the SP induced increase in Isc was diminished by preincubation with TTX or IM. However, TTX and IM had no additive effect of the SP-induced Isc increase. Application of NPY or SOM had no effect on the Isc neither under control conditions nor on epithelia prestimulated with CA or VIP. We conclude that the submucous neurones in the porcine proximal colon predominately exert stimulatory actions onto the epithelial secretion. These prosecretory effects might be directly induced by acetylcholin, NO or VIP. The prosecretory action of SP involves other submucous neurones and/or immune cells. 


\section{Melatonin effect on serotonin transporter in Caco-2 cells}

Nyurky Matheus, Carmen Mendoza, Ruth Iceta, Eva Latorre, José E. Mesonero, Miguel .A Plaza, Pilar. Arruebo, Divina Murillo, Marta Castro, Laura Grasa, Ana Isabel Alcalde

Physiology. Department of Pharmacology and Physiology. Faculty of Veterinary Sciences. Zaragoza. Spain

Serotonin (5-Hydroxytryptamine, 5-HT) is a neuromodulator mainly produced in the gastrointestinal tract. The effects of 5-HT depend on 5-HT availability which is, in part, modulated by the serotonin transporter (SERT). This transporter provides an efficient 5-HT uptake after release and is expressed in the membrane of the enterocytes. Gastrointestinal 5-HT and melatonin are two closely related neuromodulators which are synthesized in the enterochromaffin cells of the intestinal epithelium and which have been shown to be involved in the physiopathology of the gastrointestinal tract. The main aim of this study was to determine whether melatonin affects SERT activity and expression, and, if so, to elucidate the mechanisms involved. Caco-2 cell line was used to carry out the study since these cells have been shown to endogenously express SERT. The cells were treated with melatonin at short (minutes) or long term (days) periods, and 5-HT uptake and transepithelial fluxes were measured. SERT expression was determined by semiquantitative RT-PCR and western blotting. The results showed that melatonin inhibited SERT activity in a dose and time-dependent way. The kinetic study showed that both $\mathrm{V}_{\max }$ and $\mathrm{k}_{\mathrm{t}}$ kinetic constants were affected, however melatonin did not alter SERT synthesis or intracellular trafficking. In addition, the melatonin effect seemed to be independent of melatonin receptors $\mathrm{MT}_{1}$ and $\mathrm{MT}_{2}$ and PKC and cAMP intracellular pathways. This study shows that melatonin modulates SERT activity, thus demonstrating the feedback system between melatonin and the serotoninergic system in the gastrointestinal tract. These results may be useful in the study of disorders in which alterations of the serotoninergic system may be involved. 


\section{MICRONUTRIENT TRANSPORT AND TOXICITY}

\section{Evidence that quercetin acts as an $\mathrm{Fe}^{2+}$ shuttle across MDCK cell plasma membranes via GLUT1.}

Evangelia Vlachodimitropoulou ${ }^{\mathrm{a}}$, Paul A Sharp ${ }^{\mathrm{b}}$, Richard J Naftalin ${ }^{\mathrm{a}}$

Departments of Physiology ${ }^{a}$ and Nutrition \& Dietetics ${ }^{b}$, King's College London, Waterloo Campus, Franklin Wilkins Building, London SE1 $9 H N$.

Introduction. The flavonone quercetin has several important properties; it is an intracellular antioxidant acting directly on oxidized substrates, it donates electrons to the transmembrane oxidoreductase DcytB, which transfers the electron to its extracellular domain where it can reduce extracellular oxidized substrates e.g. Fe ${ }^{3+}$ to membrane permeable $\mathrm{Fe}^{2+}$ (McKie et al. 2001, Science). Quercetin is both a high affinity inhibitor of glucose transport via GLUT1, 3 and 4 and also binds at several sites within the central pore of GLUTs via which it is transported (Strobel et al. 2005, Biochem J; Cunningham et al. 2006, J Biol Chem). Unlike ascorbate, quercetin acts as a high affinity $\mathrm{Fe}^{2+}$ and $\mathrm{Fe}^{3+}$ chelator, in both extracellular and intracellular solutions, and thereby strongly attenuates Fenton reactions between $\mathrm{Fe}^{2+}$ and $\mathrm{H}_{2} \mathrm{O}_{2}$ that produce severely cytotoxic hydroxyl radicals $(\mathrm{OH})$. Since quercetin is both membrane permeable via GLUTs and a high affinity $\mathrm{Fe}^{2+}$ chelator, we speculated that it might act as a transmembrane $\mathrm{Fe}^{2+}$ shuttle via the GLUT1 transporter.

Methods. To test this hypothesis we loaded MDCK cells overnight with $\mathrm{FeSO}_{4}(10 \mu \mathrm{M})$, which were then washed free of extracellular $\mathrm{Fe}^{2+}$ with $\mathrm{PBS}$ solutions containing the impermeant $\mathrm{Fe}^{2+}$-specific chelator desferrioxamine (DFO), $300 \mu \mathrm{M}$. We then incubated the $\mathrm{Fe}^{2+}$-loaded cells with varying concentrations of quercetin (0-100 $\mu \mathrm{M})$, which was then removed by a further wash in quercetin-free solution containing both DFO and albumin $(500 \mu \mathrm{M})$, which binds quercetin and thereby facilitates its extraction from cells. Cytosolic $\mathrm{Fe}^{2+}$ activity was determined by measuring $\mathrm{Fe}^{2+}$-dependent luminescence following addition of $100 \mu \mathrm{M} \mathrm{H}_{2} \mathrm{O}_{2}$ and the $\mathrm{OH}$-sensitive luminescence probe LO12 to the cells (Wyman et al. 2008, FEBS Lett). Additionally, the calibrated $\mathrm{Fe}^{2+}$ content of cell lysates, was measured either with the ferrozine reaction, or with the $\mathrm{Fe}^{2+}$ dependent LO12 luminescence, following addition of $100 \mu \mathrm{M} \mathrm{H}_{2} \mathrm{O}_{2}$.

Results. $\mathrm{Fe}^{2+}$ accumulation into cytosol showed a hyperbolic increase following $12 \mathrm{~h}$ incubation (half maximal $\mathrm{Fe}^{2+}$ loading concentration $\left.=22 \pm 2 \mu \mathrm{M}\right)$. Using a constant $\mathrm{Fe}^{2+}$ loading concentration $(10 \mu \mathrm{M})$ and loading time (12 hours) quercetin incubation for periods of 2, 4 and 12 hours had a biphasic concentration effect on residual $\mathrm{Fe}^{2+}$ remaining within cytosol. In the range 0-0.1 $\mu \mathrm{M}$ quercetin, residual cytosolic $\mathrm{Fe}^{2+}$ fell proportionally to $25 \%$ of the level without quercetin. Raising quercetin above $0.1 \mu \mathrm{M}$ reduced $\mathrm{Fe}^{2+}$ extraction $^{2}$ until with $50 \mu \mathrm{M}$ quercetin there is zero $\mathrm{Fe}^{2+}$ extraction. Cytochalasin $\mathrm{B}(10 \mu \mathrm{M})$ or phloretin $(10 \mu \mathrm{M})$ prevent quercetin $(0.1 \mu \mathrm{M})$ dependent $\mathrm{Fe}^{2+}$ extraction, indicating that the route of quercetin dependent $\mathrm{Fe}^{2+}$ in the case of MDCK cells is via GLUT1.

Discussion and Conclusions. The limitations of current chelotherapy to reduce total body iron load are the impermeability of chelating agents, lack of oral bioavailability e.g. desferrioxamine (DFO) and possible hepatotoxicity e.g. deferriprone (DPO). Low concentrations of quercetin are orally bioavailable, membrane permeable and non-toxic, so might be useful in treatment of iron overload conditions e.g. thalassaemia not only to reduce $\mathrm{Fe}^{2+}$ induced toxicity but also the tissue iron load. 


\section{Zinc transporters in the GI tract: expression and localization of members of the ZnT subfamily}

Chiara Murgia ${ }_{2}$ Chiara Devirgiliis, Diana Bellovino, Guido Leoni, Giulia Ranaldi, Giuditta Perozzi.

INRAN - National Research Institute on Food \& Nutrition, Roma, Italy

Zinc is an essential micronutrient absorbed from the diet through the intestinal epithelium with the aid of specialized multi-span membrane transport proteins. $\mathrm{Zn}$ ions are necessary for virtually all cells and tissues in the body, being required for over 300 enzymatic activities, as well as for proper functioning of several regulatory and structural proteins. We have focused our research on the characterization of a subset of zinc transporters belonging to the SLC30A family and sharing several features, namely ZnT2, ZnT4 and ZnT8. These proteins share a quite high degree of structural and sequence homology, display different tissue-specificities, and they are all localized in the membrane of intracellular vesicles where $\mathrm{Zn}$ ions are accumulated for storage or required for specific functions. We have cloned ZnT4 as an inducible gene during intestinal differentiation. It was later reported that a point mutation in this gene represents the molecular basis of the lethal milk mouse syndrome, characterized by defective zinc secretion in the milk of lactating dams. We have studied the intestinal phenotype of ZnT4 $\mathrm{lm} / \mathrm{lm}$ mice, proposing a compensatory zinc transport activity by the highly homologous transporter ZnT2. Our recent work is focused on the third member of this subfamily, which is mainly expressed in the endocrine pancreas. We have identified the functional form of ZnT8 as a homodimer resistant to dissociation by denaturing and reducing agents, which is properly assembled only in the presence of biological membranes. Evidence will be presented indicating that members of the $\mathrm{ZnT} 2-4-8$ subfamily are able to associate in multimeric complexes. We are presently investigating through computer modelling and site-directed mutagenesis the potential role of specific aminoacid residues in affecting the stability of ZnT homodimers, with particular attention to cysteine residues, most likely involved in disulfide bridge formation.

Work supported by grant NUME (DM 3688/7303/08) from the Italian Ministry of Agriculture, Food \& Forestry (MiPAAF). 


\section{Cell growth density affects the response to copper treatment of Caco-2 differentiated monolayer}

Manuela Natoli ${ }^{\mathrm{a}}$, Bruno Leoni ${ }^{\mathrm{a}}$, Igea D’Agnano ${ }^{\mathrm{a}}$, Rossella Brandi ${ }^{\mathrm{b}}$, Ivan Arisi ${ }^{\mathrm{b}}$, Armando Felsani ${ }^{\mathrm{a}}$, Maria Flavia Zucco ${ }^{\mathrm{a}}$

${ }^{a}$ CNR, Institute of Neurobiology and Molecular Medicine. ${ }^{b}$ European Brain Research Institute, Rome, Italy.

The human intestinal Caco-2 cell line has been extensively used as a model of the intestinal barrier. However, it is widely reported in literature that culture-related conditions, as well as the different Caco-2 cell lines utilized in different laboratories, often lead to problems of reproducibility making difficult to compare results. We developed a new protocol in which Caco-2 cells were subcultured at $50 \%$ of confluence (Low Density, LD) instead of $90 \%$ of confluence, as usually reported in literature (High Density, HD). Using this new protocol, Caco-2 cells preserved a higher proliferation potential resulting in a cell population, which, reaching confluence was able to differentiate almost synchronously, forming a more homogeneous and perfectly polarized cell monolayer, as compared to that obtained with the HD cells. This comparison has been done by analyzing the gene expression and the structural characteristics of the 21-days differentiated monolayers by microarrays hybridization and by confocal microscopy. We investigated if these structural differences could also influence the effects of toxicants on 21-days-differentiated LD and HD cells. We analyzed the 2 hours-acute toxicity of $\mathrm{CuCl}_{2}$ in terms of actin depolymerization and MT2A (metallothionein 2A) and HSPA1A (heat shock protein 70) genes induction. Copper treatment resulted in different levels of actin depolymerization and gene expression induction in relationship with the culture protocol, the LD cells showing a more homogeneous and stronger response. Moreover, it is worthwhile to note, that in all these experiments, which have been repeated many times, the response of LD cells were always more reproducible and constant compared to the HD one. Our results suggest that different cell line maintenance protocols could influence a number of morphological and physiological properties of differentiated Caco-2 cells and these effects must be taken in account when these cells are used as intestinal model.

Work supported by EU FP6 Project “LIINTOP” Contract number LSHB-CT-2006-037499. 


\section{Phytosterols impair vitamin $D_{3}$ uptake in Caco-2 cells}

Aurélie Goncalves, Romain Bott, Patrick Borel, Emmanuelle Reboul

UMR 1260 INRA-Université de Méditerranée, ERL 1025 INSERM, Marseille, France

Background: Adequate vitamin D status is necessary and beneficial for health, although deficiency and insufficiency are very common. Indeed, in addition to reducing the risk for bone disease, vitamin D likely plays a role in autoimmune diseases, cancer, heart disease, mortality, and cognitive function.

Phytosterols are commonly used in the diet to decrease cholesterol intestinal absorption in order to diminish hypercholesterolemia. As vitamin D displays a chemical structure close to the structure of cholesterol, we hypothesized that phytosterols may interact with vitamin D intestinal absorption as well.

Objective: Our aim was to evaluate the effect of cholesterol as well as the 3 main dietary phytosterols ( $\beta$ sitosterol, stigmasterol and campesterol) on micellar cholecalciferol (vitamin $\mathrm{D}_{3}$ ) uptake in human intestinal cells.

Methods: We used differentiated Caco2-TC7 cell monolayers grown on filters. Cholecalciferol-rich mixed micelles, supplemented or not in sterol, were added to the cells for $60 \mathrm{~min}$. A particular care was given to respect a ratio vitamin $\mathrm{D} /$ sterol close to the one observed in the diet. Cholecalciferol was then measured in rinsed scrapped cells and in basolateral medium (if any) by HPLC to evaluate its uptake.

Results: Cholesterol, $\beta$-sitosterol, stigmasterol and campesterol could significantly inhibit cholecalciferol uptake (up to $40 \%$ ).

Conclusion: Sterols impaired vitamin D uptake in Caco-2 cells at physiological conditions. Further investigations are needed to assess if this effect is dose-dependent and to validate these results in vivo. 


\title{
Influence of a reduced nitrogen diet on intestinal electrolyte transport in young goats
}

\author{
Alexandra Muscher, Mirja Wilkens, Nina Mrochen, Gerhard Breves, Bernd Schröder, Korinna Huber
}

Department of Physiology, University of Veterinary Medicine Hannover, Germany

From monogastric animals and humans it is known that changes in dietary protein content can cause adaptive changes in electrolyte metabolism. A reduction of intestinal absorption of calcium (Ca) could be observed in monogastric animals and humans fed with a low protein diet. In ruminant feeding, one aim is to reduce environmental nitrogen $(\mathrm{N})$ pollution by reducing dietary $\mathrm{N}$ intake. Since ruminants express recycling mechanisms very efficiently for saving $\mathrm{N}$, it is expected that these recycling mechanisms protect ruminants in times of dietary $\mathrm{N}$ restriction. The aim of the present study was to determine whether there is an interaction between $\mathrm{N}$ and electrolyte homeostasis changing the intestinal absorption of electrolytes in N-restricted goats. Male white Saanen goats were fed either with an adequate $(19.3 \%, n=7)$ or reduced $\mathrm{N}$ diet $(6.7 \%, \mathrm{n}=6)$. Plasma concentrations of phosphate $\left(\mathrm{P}_{\mathrm{i}}\right)$ and total Ca were determined colorimetrically. Ionized Ca was detected by an ion-selective electrode. Epithelia from the proximal and mid jejunum were mounted into Ussing chambers. Radioactive tracers ${ }^{45} \mathrm{Ca}$ or ${ }^{32} \mathrm{P}$ were used to calculate unidirectional $\mathrm{Ca}$ and $\mathrm{P}_{\mathrm{i}}$ flux rates. Flux measurements were done under short circuited conditions. Additionally, segments of proximal and mid jejunum were taken for preparation of brush border membrane vesicles (BBMV). Concentration dependent uptakes of Ca or $\mathrm{P}_{\mathrm{i}}$ into BBMV were measured by rapid filtration technique. Total $\mathrm{Ca}$ concentrations as well as ionized Ca were significantly decreased by changes in dietary $\mathrm{N}$ content. In jejunum, significantly higher $\mathrm{Ca}$ and $\mathrm{P}_{\mathrm{i}}$ fluxes were detected in goats fed a reduced $\mathrm{N}$ diet. The capacities of both apically located transport systems as well as their transporter affinities were not affected. Therefore, it can be concluded that the intestinal absorption of electrolytes in goats is affected by changes in dietary $\mathrm{N}$ levels like in monogastric animals even though it is known that ruminants have efficient recycling mechanisms. However, the discrepancy between the data obtained from the Using chambers in comparison to the uptake studies cannot be explained yet. Alterations in intracellular events and/or changes in the basolateral side must be considered. 


\section{Relationship between acetate and butyrate transport in the ruminal epithelium of sheep}

Gregory B Penner ${ }^{\mathrm{a}}$, Gotthold Gäbel ${ }^{\mathrm{b}}$, Reiko Rackwitz ${ }^{\mathrm{b}}$, Joerg R Aschenbach ${ }^{\mathrm{c}}$.

${ }^{a}$ Dept. of Animal and Poultry Science, Univ. of Saskatchewan, Saskatoon, Canada; ${ }^{b}$ Inst. of Veterinary Physiology, Univ. of Leipzig, Germany; 'Inst. for Physiology, Pathophysiology and Biophysics, Univ. of Veterinary Medicine Vienna, Austria

Apical uptake of acetate into ruminal epithelia of sheep comprises at least three components differing in their $\mathrm{HCO}_{3}{ }^{-}$dependence and $\mathrm{NO}_{3}{ }^{-}$sensitivity. The present study aimed to elucidate whether butyrate has related transport modes.

Materials and Methods: The transepithelial flux rates of $\left[{ }^{3} \mathrm{H}\right]$-acetate and $\left[{ }^{14} \mathrm{C}\right]$-butyrate $(10 \mathrm{mM}$ each) were determined in parallel in isolated ruminal epithelia of 17 sheep using Ussing chambers. In separate epithelia from the same sheep, apical uptakes of $\left[{ }^{3} \mathrm{H}\right]$-acetate and $\left[{ }^{14} \mathrm{C}\right]$-butyrate were determined in parallel. The chloridefree incubation buffer had a mucosal and serosal $\mathrm{pH}$ of 6.1 and 7.4, respectively. Bicarbonate-dependent (BD) flux or uptake was calculated as the difference between measurements in the presence $(24 \mathrm{mM})$ and absence of $\mathrm{HCO}_{3}^{-}$. Bicarbonate-independent (BI) flux or uptake was further divided into $\mathrm{NO}_{3}^{-}$-sensitive (NS) and $\mathrm{NO}_{3}^{-}$ insensitive (NI) components based on flux or uptake inhibition by $40 \mathrm{mM} \mathrm{NO}_{3}^{-}$.

Results: The total flux rate was higher for butyrate compared to acetate ( $2.70 \pm 0.15$ vs. $1.17 \pm 0.10 \mu \mathrm{mol}$ $\left.\cdot \mathrm{cm}^{-2} \cdot \mathrm{h}^{-1} ; P<0.05\right)$. This was linked to higher BD $\left(1.14 \pm 0.14\right.$ vs. $\left.0.68 \pm 0.10 \mu \mathrm{mol} \cdot \mathrm{cm}^{-2} \cdot \mathrm{h}^{-1} ; P<0.05\right)$ and BI-NI components of flux rate $\left(1.84 \pm 0.15\right.$ vs. $\left.0.40 \pm 0.02 \mu \mathrm{mol} \cdot \mathrm{cm}^{-2} \cdot \mathrm{h}^{-1} ; P<0.05\right)$. By contrast, the BI-NS component of flux rate was smaller and negative for butyrate compared to acetate $(-0.43 \pm 0.19$ vs. $0.084 \pm 0.18$ $\left.\mu \mathrm{mol} \cdot \mathrm{cm}^{-2} \cdot \mathrm{h}^{-1} ; P<0.05\right)$. Total flux rates of butyrate and acetate $(r=0.91)$, as well as their BD $(r=0.69)$ and BI-NI components $(r=0.61)$ were positively correlated $(P<0.01)$, while the BI-NS components were negatively correlated $(r=-0.53 ; P<0.05)$. Similar results were obtained for the uptakes of butyrate and acetate, except for an absent negative correlation between the BI-NS components $(r=0.34)$.

Conclusion: The results point to a common bicarbonate-dependent transport mechanism for butyrate and acetate. The BI-NS component could represent a nitrate-sensitive protein that is capable of acetate/butyrate exchange, at least, under steady state conditions and in the absence of chloride and bicarbonate. 


\section{Changes in ion transport induced by the endogenous $\mathrm{H}_{2} \mathrm{~S}$ donor, cysteine, across rat}

\section{distal colon}

Ervice Pouokam, Martin Diener

Institute for Veterinary Physiology, Justus-Liebig-University Giessen, Germany

Recently, we have shown that an exogenous $\mathrm{H}_{2} \mathrm{~S}$ donor, NaHS, induces a triphasic change in short-circuit current (Isc) across rat distal colon (Brit. J. Pharmacol. 158: 1263-1275, 2009) which consists of an initial, transient increase in Isc, a secondary decrease and a long-lasting final increase in current. As the presence of the enzymes for endogenous $\mathrm{H}_{2} \mathrm{~S}$ formation, cystathionine- $\beta$-synthase (CBS) and cystathionine- $\gamma$-lyase (CSE), was detected within the colonic epithelium, in the present study we asked the question, whether a stimulation of endogenous $\mathrm{H}_{2} \mathrm{~S}$ production by the substrate for these enzymes, i.e. cysteine, might also affect ion transport and in this case, the study of the mechanisms involved. In Ussing chamber experiments, L-cysteine $(1-10 \mathrm{mM})$ induced a concentration-dependent monophasic decrease in Isc across rat distal colon. This response was inhibited in the combined presence of the CBS inhibitor, amino-oxyacetate ( $5 \mathrm{mM}$ ), and the CSE inhibitor, $\beta$-cyano-L-alanine (5 $\mathrm{mM})$. An increase in Isc, i.e. an anion secretion as it was induced by NaHS, was not evoked, i.e. only the second phase of the NaHS response could be mimicked by stimulation of endogenous $\mathrm{H}_{2} \mathrm{~S}$ production. The response was not sensitive to tetrodotoxin and could be evoked several times at the same epithelium without desensitization.Anion substitution and transport blocker experiments with bumetanide $(100 \mu \mathrm{M})$ suggest that the decrease in Isc evoked by cysteine is caused by an inhibition of spontaneous $\mathrm{Cl}^{-}$secretion. The decrease in Isc could also be prevented, when basolateral $\mathrm{K}^{+}$conductance was inhibited by $\mathrm{K}^{+}$channel blockers such as tetrapentylammonium $(100 \mu \mathrm{M})$ or $\mathrm{Ba}^{2+}(10 \mathrm{mM})$. Blockade of apical $\mathrm{K}^{+}$channels did not affect the effect of cysteine ruling out an induction of $\mathrm{K}^{+}$secretion by cysteine. Experiments with isolated colonic crypts loaded with fura- 2 revealed that cysteine induced a biphasic change in the cytosolic $\mathrm{Ca}^{2+}$ concentration: a transient increase followed by a sustained fall. It is assumed that the resulting decrease of basolateral $\mathrm{Ca}^{2+}$-dependent $\mathrm{K}^{+}$ conductance is the reason for the inhibition of spontanous anion secretion by cysteine. 


\section{Epithelial secretion of the porcine proximal colon is stimulated by submucous neurotransmitters}

Anja Mauksch, Gotthold Gäbel, Helga Pfannkuche

Institute of Veterinary-Physiology, Leipzig University, Germany

Various epithelial functions in the gastrointestinal tract are controlled by neurotransmitters of the enteric nervous system. Since secretory diarrhea is a common problem in pigs, we focused on the pro- and antisecretory actions of neurotransmitters derived from submucous neurones of the porcine proximal colon. The presence of the putative neurotransmitters was shown by indirect immunofluorescence staining of cryostat sections. Antibodies against the following antigens were used, choline-acetyltransferase (ChAT), nitric oxide synthase (NOS), substance P (SP), vasoactive intestinal peptide (VIP), neuropeptide Y (NPY) and somatostatin (SOM). All off these neurotransmitters were found in fibres and neuronal somata of the submucous plexus. A strong expression on nerve fibres projecting into the epithelial layers was seen for VIP, NPY and SP. Expression of ChAT was not only found on neuronal structures but also within the enterocytes. To evaluate whether these neurotransmitters were able to stimulate or inhibit epithelial secretion, mucosa-submucosa preparations were mounted in Ussing chambers under short circuit conditions. Increase in short circuit current (Isc) was taken for epithelial electrogenic secretion. Serosal application of carbachol (CA, cholinergic agonist), sodium nitroprussid (NO donor), SP or VIP induced a significant increase in Isc. Preincubation with tetrodotoxin (TTX) or indomethacin (IM) did not alter the effect of CA, NO or VIP. In contrast, the SP induced increase in Isc was diminished by preincubation with TTX or IM. However, TTX and IM had no additive effect of the SP-induced Isc increase. Application of NPY or SOM had no effect on the Isc neither under control conditions nor on epithelia prestimulated with CA or VIP. We conclude that the submucous neurones in the porcine proximal colon predominately exert stimulatory actions onto the epithelial secretion. These prosecretory effects might be directly induced by acetylcholin, NO or VIP. The prosecretory action of SP involves other submucous neurones and/or immune cells. 


\section{Two novel colonic mineralocorticoid receptor cell models expressing functional epithelial $\mathrm{Na}^{+}$channels}

Theresa Bergann ${ }^{\mathrm{a}}$, Anja Fromm ${ }^{\mathrm{b}, \mathrm{c}}$, Svenja Plöger ${ }^{\mathrm{a}}$, Sebastian Zeissig ${ }^{\mathrm{a}, \mathrm{d}}$, Tim Ziera ${ }^{\mathrm{e}}$, Steffen A Borden ${ }^{\mathrm{e}}$, Michael Fromm $^{\mathrm{c}}$, Jörg D Schulzke ${ }^{\mathrm{a}, \mathrm{b}}$

${ }^{a}$ Dept. of Gastroenterology, Infectious Diseases and Rheumatology; ${ }^{b}$ Dept. of General Medicine; ${ }^{c}$ Inst. of Clinical Physiology, Charité Berlin, Germany; ' Gastroenterology Division, Brigham \& Women's Hospital, Boston, USA; ${ }^{e}$ Bayer Schering Pharma, Berlin, Germany

In the distal colon, the epithelial sodium channel $(\mathrm{ENaC})$ is rate limiting for sodium absorption. Progress in the molecular characterization of $\mathrm{ENaC}$ expression and trafficking in response to the mineralocorticoid aldosterone has been hampered, since no epithelial colonic cell line existed expressing functional $\mathrm{ENaC}$ stimulated by nanomolar aldosterone via the mineralocorticoid receptor (MR). Here, we present two novel human colonic epithelial cell lines expressing the MR (HT-29/B6-Tet-On-MR and HT-29/B6-GR-MR) which exhibit ENaC-mediated sodium transport in response to aldosterone. Both cell lines were derived from the colonic cell line HT-29/B6, which grow as polarized epithelial monolayers and lack both glucocorticoid and mineralocorticoid receptor expression. The first cell line (HT-29/B6-Tet-On-MR) inducibly expresses the MR by the use of the Tet-On ${ }^{\circledR}$ Inducible Gene Expression System. Here, the presence of the short-chain fatty acid butyrate was necessary for the generation of an aldosterone-dependent ENaC-mediated $\mathrm{Na}^{+}$transport. Characterizing the underlying mechanisms, we found butyrate to be responsible for high-level expression of the MR which allowed for aldosterone-dependent upregulation of $\beta$ - and $\gamma$-ENaC expression. The second cell line (HT-29/B6-GR-MR) stably co-expresses the MR with the glucocorticoid receptor (GR). In these cells, coincubation with butyrate could be circumvented by a pre-incubation step with the GR agonist dexamethasone to yield aldosterone-induced $\mathrm{ENaC}$-dependent $\mathrm{Na}^{+}$transport as well as enhanced $\beta$ - and $\gamma$-ENaC expression levels. In both cell lines, aldosterone-induced GILZ (glucocorticoid-induced leucine zipper protein) was identified as a candidate factor increasing apical $\mathrm{ENaC}$ levels which were essential for the induction of significant $\mathrm{Na}^{+}$transport rates. 


\section{Functional characterization of IPEG-J2 Monolayer (as a model for native porcine epithelium)}

Andre Kacholdt, Mandy Bruch, Hanka Sanftleben, Annette Zeyner, Elmar Mohr

University of Rostock, Germany

Background: In previous works native porcine epithelia was used to simulate the transport of proteins (GFP green fluorescent protein) from the gut into the blood. Because of the underlying biological unevenness of the tissue, transport rates of GFP were characterized by high inter- and intraindividual variability To minimize this effect, a cell culture (IPEG-J2) model was establish.

Methods: Cells growing in DMEM/Ham's F12 with $15 \%$ foetal calf serum and $36 \mathrm{mM}$ sodium bicarbonate on a polyester membranes with $0.4 \mu \mathrm{m}$ pores (corning costar 3801). TEER (Transepithelial electric resistance) values and the diffusion of ${ }^{3} \mathrm{H}$-manitol were measured. The transport rates of four essential ${ }^{3} \mathrm{H}$ amino acids (Methionine M, Leucin L, Lysin K and Thyrosin Y) were determined. Also transport of small intact proteins (e.g. GFP) was investigated.

Results: The maximum of TEER and the minimum of diffusion of Mannitol (standard permeability coefficient $\mathrm{P}_{\text {app }}$ ) have been reached on day eight after seeding (with a concentration of $600000 \mathrm{cells} / \mathrm{mm}$ ). There was a transport of amino acids, glucose and sodium ions. In addition, first results showed transport of intact GFP, too. Glucose and sodium transport was detected in ussing-chamber by measuring electrical current. GFP transport was detected in the same system but measured by ELISA. Determining the kind of transport, further experiments are necessary. All described transports could also be detected on the native porcine epithelium.

Conclusions: The monolayer has the highest TEER values and the lowest $\mathrm{P}_{\text {app }}$ values on day eight. Transport of glucose, sodium and amino acids is similar to native tissues. Therefore, the cell culture model could be appropriate for transport investigations.

The project is supported by $B M B F$. 


\section{Primary rat enterocytes as a useful tool for the evaluation of drug uptake}

Caroline MacLean ${ }^{\mathrm{a}}$, Ulla Moenning ${ }^{\mathrm{b}}$, Andreas Reichel ${ }^{\mathrm{b}}$, Gert Fricker ${ }^{\mathrm{a}}$

${ }^{a}$ Pharmaceutical Technology and Biopharmacy, Institute of Pharmacy and Molecular Biotechnology, University of Heidelberg, Germany

${ }^{b}$ Research Pharmacokinetics, Bayer Schering Pharma AG, Berlin, Germany

The absorption of an orally administered drug across the intestinal epithelium is one key factor for its bioavailability. It is well known that efflux transporters located in the enterocytes can limit or prevent the absorption of drugs into the systemic circulation. However, current development suggests that the oral bioavailability of many emerging drugs depends on active uptake into enterocytes. Therefore, a cell-based system of the intestinal barrier that displays relevant active uptake transporters would be a useful tool for drug discovery. For that purpose rat enterocytes were isolated and evaluated regarding their potential for carriermediated uptake using radiolabeled substrates for various transport systems. We have used digoxin as a substrate for Oatps, glycylsarcosine as a substrate for the peptide transporter PepT1, and L-leucine as a model substrate of amino acid transporters. As expected, digoxin showed a temperature sensitive uptake into isolated enterocytes but with an even higher uptake at $4{ }^{\circ} \mathrm{C}$ compared to $37^{\circ} \mathrm{C}$. Interestingly, it was the uptake that could be inhibited by PSC-833 and elacridar which are more known as inhibitors of Pgp. In addition, using glycylsarcosine it could be shown that the peptide transporter PepT1 is very active in primary enterocytes. The uptake was $\mathrm{pH}$ sensitive, and could be competitively inhibited by Gly-Gly. Furthermore, primary enterocytes also showed active uptake of L-leucine which was sodium-independent and could be inhibited by $\mathrm{BCH}$ which is a specific inhibitor for system $\mathrm{L}$ type amino acid transporters. Taken together, these data indicate that isolated primary rat enterocytes express several uptake transporters, which may be relevant for the active intestinal absorption of drugs. Therefore, this primary cell model may be a suitable tool for evaluating absorption behaviour of drug discovery compounds. 


\title{
The intestine of marine teleosts: a model to study bicarbonate secretion.
}

\author{
Caterina Faggio, Agata Torre, Grazia Di Fresco, Francesca Trischitta.
}

Dipartimento Di Scienze della vita "M.Malpighi". Università di Messina. Viale Ferdinando Stagno d'Alcontres, 31-98166 S.Agata, Messina.

Marine teleosts, living in a hyperosmotic environment, undergo a continuous water loss. Dehydration is prevented by drinking seawater at high rate and by absorbing the fluid, desalinated at esophageal level, across the intestinal epithelium. In order to reduce the osmolality of the intestinal fluid and to minimize the intestinal absorption of excess calcium, this epithelium performs an active $\mathrm{HCO}_{3}{ }^{-}$secretion to precipitate the large amount of $\mathrm{Ca}^{++}$present in the hypercalcemic external medium. In the present study, performed on the Dycentrarchus labrax, we evaluated the possibility to study the mechanism of active $\mathrm{HCO}_{3}{ }^{-}$secretion in the isolated intestine mounted in Ussing chamber. Bicarbonate secretory fluxes were evaluated by the $\mathrm{pH}$-stat method under short circuit conditions. We found that the tissue is able to secrete $\mathrm{HCO}_{3}{ }^{-}$at a rate of $2.1 \pm 0.1 \mu \mathrm{eq} \cdot \mathrm{cm}^{-2} \cdot \mathrm{h}^{-1}(\mathrm{n}=6)$ for at least three hours. This flux was dependent on the serosal $\mathrm{Na}^{+}$and was inhibited by both luminal and serosal DIDS. In order to determine the contribution of carbonic anhydrase in $\mathrm{HCO}_{3}{ }^{-}$secretion, experiments employing acetazolamide were performed. The role of transepithelial bicarbonate transport was tested in experiments performed in the absence of serosal $\mathrm{HCO}_{3}{ }^{-}$and $\mathrm{CO}_{2}$. The results obtained suggest that the main source of $\mathrm{HCO}_{3}{ }^{-}$ secreted is the extracellular $\mathrm{HCO}_{3}{ }^{-}$transported across the intestinal epithelium. The serosal uptake probably takes place by means of DIDS inhibitable $\mathrm{Na}^{+}$-dependent mechanism, while an apical $\mathrm{Cl}^{-}-\mathrm{HCO}_{3}{ }^{-}$exchanger transports the base into the lumen. These preliminary data suggest that marine teleost intestine may be an interesting tool for studying "in vitro" active epithelial $\mathrm{HCO}_{3}{ }^{-}$secretion since it is an easily accessible organ of suitable size for experimentation. It may provide an useful model for mammalian $\mathrm{HCO}_{3}{ }^{-}$secretory epithelia. 


\section{Fluorimetric analysis of copper transport mechanisms in B104 neuroblastoma cell} model: a contribution from cellular prion protein to copper supplying

Emanuela Urso ${ }^{a}$, Antonia Rizzello ${ }^{a}$, Raffaele Acierno ${ }^{a}$, Maria Giulia Lionetto ${ }^{a}$, Benedetto Salvato ${ }^{b}$, Carlo Storellia ${ }^{\mathrm{a}}$, Michele Maffia ${ }^{\mathrm{a}}$

${ }^{a}$ Department of Biological and Environmental Science and Technology, University of Salento, via Monteroni, 73100 Lecce, Italy; ${ }^{\mathrm{b}}$ Department of Biology, University of Padova, via U. Bassi 58/B, 35121 Padova, Italy

Dysregulated body copper homeostasis can negatively impact neuronal functions, but full knowledge of the mechanisms underlying the cell metal distribution has not been achieved yet. The high-affinity copper transporter $1(\mathrm{Ctr} 1)$ is considered the main route for cell copper entry, while the cellular prion protein $\left(\operatorname{PrP}^{\mathrm{C}}\right)$ is presumed to be involved in the same process. Anchored to the outer side of the plasma membrane, this protein has the ability to bind copper ions and undergo internalization. To provide indications about the contribution of $\mathrm{Ctr} 1$ and $\mathrm{PrP}^{\mathrm{C}}$ proteins in cell copper transport, we used a fluorimetric method to characterize the kinetic properties of ion internalization in a neuroblastoma cell model, overexpressing prion protein (B104). Biochemical characteristics of intake delineated in the presence of other metal ions and an excess of extracellular potassium were compatible with $\mathrm{PrP}^{\mathrm{C}}$-mediated endocytotic transport. Accordingly, inhibition of clathrindependent endocytosis by hypertonic shock and enzymatic removal of surface prion protein reduced copper influx by the same extent. On the whole, experimental evidence collected in B104 neuron-like cell model sustains a role for $\operatorname{PrP}^{\mathrm{C}}$ in mediating copper uptake by clathrin-dependent endocytosis. Further work is in progress aimed at investigating the mechanisms of transepithelial copper transport across Caco-2 cells as a model of intestinal absorption. 


\title{
Identification of novel inhibitors of intestinal phosphate transport: a potential approach to controlling hyperphosphataemia in chronic renal failure
}

\author{
Johanne Marks, Robert J Unwin, Edward S Debnam
}

London Epithelial Group, University College London, London, UK

Hyperphosphataemia is a serious consequence of chronic renal failure (CRF), leading to vascular calcification and increased cardiovascular morbidity and mortality. Targeting the kidney to reduce hyperphosphataemia in CRF is limited due to reduced renal function. Therefore, inhibiting intestinal phosphate absorption is a potential strategy for preventing phosphate overload in CRF. Currently, four phosphatonins have been identified: fibroblast growth factor 23 (FGF-23), matrix extracellular phosphoglycoprotein (MEPE), fibroblast growth factor 7 (FGF-7), and secreted frizzled related protein 4 (sFRP-4); all of which have been shown to have a potent inhibitory action on renal phosphate reabsorption. However, there is little information about the effects of phosphatonins on intestinal phosphate uptake. Our previous research has shown that MEPE acutely inhibits intestinal phosphate absorption independently of known regulators of phosphate homeostasis. The current study used an in vivo gut loop technique to show that two other phosphatonins have a similar inhibitory action on jejunal phosphate absorption. Thus, intravenous infusion of FGF-23 or sFRP-4 over a $3 \mathrm{hr}$ period significantly decreased lumen to blood phosphate transfer to $67 \pm 1.8 \%(\mathrm{P}<0.01)$ and $72 \pm 4.1 \%$ $(\mathrm{P}<0.05)$, respectively, compared with animals infused with vehicle only $(90 \pm 6 \%)$. In contrast, FGF-7 infusion failed to evoke a significant change in phosphate absorption ( $80 \pm 4.1 \%)$.

These results demonstrate that three of the four known phosphatonins inhibit intestinal phosphate absorption in vivo. Studies are underway to investigate their potential to inhibit phosphate absorption in CRF as a means of controlling the associated hyperphosphataemia.

We are grateful to Kidney Research UK for providing funding for this research. 


\section{PiT transporters are regulated by age and diet}

Sobiya P Nadaraja ${ }^{\mathrm{a}}$, Johanne Marks ${ }^{\mathrm{a}}$, David Rosen ${ }^{\mathrm{b}}$, Robert J Unwin ${ }^{\mathrm{a}}$, Edward S. Debnam ${ }^{\mathrm{a}}$.

${ }^{a}$ London Epithelial Group, University College London, London, UK; ${ }^{b}$ Acologix Inc, Hayward, CA, USA

Both kidney and small intestine (SI) contribute to phosphate (Pi) homeostasis; the uptake process in these tissues is known to be influenced by age and dietary Pi intake. A low Pi diet promotes the expression of NaPi-IIa and $\mathrm{NaPi}$-IIc proteins at the rat renal brush border membrane (BBM) and NaPi-IIb at the intestinal BBM; renal NaPi-IIc is preferentially expressed during weaning, but does not seem to play a major role in Pi reabsorption in the adult. The effects of age and dietary Pi intake on gene expression of the type III transporters PiT1 and PiT2 in kidney are unknown. In the SI, studies show age-related decreases in NaPi-IIb, but involvement of PiT proteins in control of Pi uptake is unclear. We examined the effects of animal maturity and a low Pi diet on gene expression of established Pi transporters. We used male Sprague-Dawley rats aged 3 (young) or 16 (adult) weeks. Some adults were fed a low Pi diet $(0.1 \%$ Pi) for 1 week. Transporter mRNA levels were quantified in renal cortex or jejunal mucosa by real-time PCR. Pi uptake across the jejunal BBM was measured using the everted sleeve technique. A low Pi diet increased renal mRNA levels of NaPi-IIa 2.4-fold ( $p<0.03$ ), but not NaPi-IIc. Interestingly the low Pi diet did not affect renal PiT1 mRNA level, but increased PiT2 mRNA expression 16-fold $(\mathrm{p}<0.05)$. Low Pi diet also increased Na-dependent Pi uptake across the jejunal BBM ( $1.87 \pm 0.19$ vs $4.95 \pm 0.73$ nmoles/100mg tissue, $\mathrm{p}<0.001)$; although, surprisingly, this was not due to altered gene expression of NaPi-IIb, PiT1 or PiT2. Pi uptake was also significantly higher in young, compared with adult rats, which was mirrored by increased mRNA expression of NaPi-IIb $(p<0.02)$ and PiT2 $(p<0.005)$. These results reveal complex differential changes in expression of Pi transporters during animal maturity and exposure to a low Pi diet, which may have implications for therapeutic targeting of Pi transport in vivo. More specifically, PiT2 assumes a dominant role in Pi transport in the jejunum of pre-weaned animals, and in the kidneys of animals fed a low Pi diet. Although PiT1 is expressed in kidney and SI, it is unlikely to be responsible for adaptive changes in Pi uptake in these tissues. 


\section{Evidence that the colon may be important in phosphate homeostasis}

Sobiya P Nadaraja ${ }^{\mathrm{a}}$, Johanne Marks ${ }^{\mathrm{a}}$, David Rosen ${ }^{\mathrm{b}}$, Robert J Unwin ${ }^{\mathrm{a}}$, Edward S. Debnam ${ }^{\mathrm{a}}$.

${ }^{a}$ London Epithelial Group, University College London, London, UK, ${ }^{b}$ Acologix Inc, Hayward, CA, USA

The importance of the small intestine ( $\mathrm{SI})$ for phosphate $(\mathrm{Pi})$ absorption is widely accepted. There is some evidence for mRNA expression of Pi transporters in colonic epithelium (personal communication, Carsten Wagner), an intestinal region that has not hitherto been associated with Pi absorption. The purpose of our present study was to compare Pi absorption in the rat SI and colon, measured under both in vivo and in vitro conditions. In vitro studies measured mucosal ${ }^{32} \mathrm{P}$ retention in everted intestinal sleeves after their incubation for 2 mins in NaCl-HEPES or choline-chloride-HEPES buffer containing ${ }^{32} \mathrm{P}(0.1-2 \mathrm{mM})$. The in situ intestinal loop technique was used to measure blood appearance of ${ }^{32} \mathrm{P}$ after instillation of $+\mathrm{Na}^{+}$or $-\mathrm{Na}^{+}$-buffer, containing ${ }^{32} \mathrm{P}$, into the lumen. In vitro results revealed a concentration-dependence of jejunal $\mathrm{Na}^{+}$-dependent Pi uptake $(0.1 \mathrm{mM}$ Pi: $1.6 \pm 0.2,0.5 \mathrm{mM}$ Pi: $6.0 \pm 0.3,2 \mathrm{mM}$ Pi: $12.3 \pm 0.9 \mathrm{nmol} / 100 \mathrm{mg}$ jejunum); a similar relationship was seen in duodenum. $\mathrm{Na}^{+}$-independent uptake was also increased at higher buffer Pi levels. Interestingly, $\mathrm{Na}^{+}$-dependence of blood appearance of ${ }^{32} \mathrm{P}$ was not seen at higher luminal Pi concentrations. Pi transport in SI could be resolved into two components; at lower Pi concentrations $(<1 \mathrm{mM})$, transport is dominated by active $\mathrm{Na}^{+}-\mathrm{Pi}$ cotransport; However at higher Pi levels (1-2 mM), Pi absorption is largely $\mathrm{Na}^{+}$-independent, which may represent a facilitated or passive transport process. At $0.5 \mathrm{mM} \mathrm{Pi}$, a 6-fold higher rate of Pi uptake, measured in vitro, was seen in distal colon compared to proximal colon ( $\mathrm{p}<0.001$ ). This amounted to $30 \%$ and $65 \%$ of uptake recorded in jejunum and duodenum respectively at the same Pi concentration. However unlike that occurring in SI, ${ }^{32} \mathrm{P}$ $(0.5 \mathrm{mM})$ uptake by the distal colon was Na-independent, both in vitro and in vivo. Taken together, these data suggest that distal colon might be an important region for Pi absorption. 


\section{Copper involvement in gene expression, secretion and biological functions of TFF1}

Sandro Montefusco ${ }^{\mathrm{a}}$, Bianca Fontanella ${ }^{\mathrm{a}}$, Roberta Esposito, Daniela Baldantoni ${ }^{\mathrm{b}}$, Alessandra Tosco ${ }^{\mathrm{a}}$, Liberato Marzullo ${ }^{\mathrm{a}}$.

${ }^{a}$ Department of Pharmaceutical Sciences - Division of Biomedicine “Arturo Leone”, 'Department of Chemistry, University of Salerno, Fisciano (SA), Italy

The Trefoil Factors Family includes the gastric peptides TFF1/(pS2), the spasmolytic peptide TFF2/(SP) and the intestinal trefoil factor TFF3/(ITF) which have an essential role in epithelial restitution within the gastrointestinal tract, where they are mainly expressed. We recently demonstrated that TFF1 is able to specifically bind copper ions through its acidic carboxy-terminal tail. Copper is an essential element for higher life forms, and plays a significant role in aerobic life as cofactor of enzymes involved in metabolically important red-ox reactions as oxidative phosphorylation, iron and oxygen transport, oxidative stress defences, collagen synthesis, etc. Our experimental evidence showed that copper binding favours the homodimerization of TFF1 protein, thus enhancing its motogenic activity. Work in progress is aimed at studying the involvement and influence of copper in $t f f 1$ gene expression, protein secretion, and biological functions. Real Time PCR analyses showed that, in the human breast cancer cell line MCF-7, copper deficiency positively modulate tffl mRNA, suggesting a regulatory role of copper in TFF1 expression. To this aim, we analyzed the regulatory role of the proximal upstream gene sequence in correlation with copper deficiency. In order to map possible copper responsive consensus elements, we analyzed the expression of the luciferase reporter gene driven by deletion constructs of the tffl gene promoter. The human gastric cancer cell line AGS, transfected with the deletion constructs, showed that the upstream 5' gene region $-686 /-472$ is responsive to the variations of copper concentration. Namely, copper chelation with bathocuproine disulfonate (BCS) is able to stimulate an increase of gene transcription when the promoter contains the upstream region from -686 to +1 , but it is not able to stimulate any increase when only $-472 /+1$ region is present. To investigate the involvement of copper in the TFF1 secretion process, we monitored the timing of TFF1 synthesis and secretion in a TFF1 inducible AGS clone (AGS-AC1). The results obtained show that copper overload delays the peptide secretion. Finally, preliminary atomic absorption analyses demonstrate that the uptake of copper in TFF1 hyper-expressing AGS-AC1 cells is faster than in non-induced cells. This evidence suggests that TFF1 levels may play a role in copper transport and homeostasis in this in vitro model.

Work supported by grant NUME (DM 3688/7303/08) from the Italian Ministry of Agriculture, Food \& Forestry (MiPAAF) and University of Salerno Intramural (ex 60\%) FARB Funds. 


\section{A protective role for zinc ions in the intestinal epithelium}

Giulia Ranaldi, Yula Sambuy, Giuditta Perozzi, Chiara Murgia.

INRAN - National Research Institute on Food and Nutrition, Roma, ITALY.

Zinc ( $\mathrm{Zn})$ is an essential micronutrient. $\mathrm{Zn}$ crosses biological membranes with the aid of specialized membrane transport proteins. Severe Zn deficiency is known to affect tight junction (TJ) integrity. Zn deficiency was often described in patients affect by chronic inflammatory intestinal syndromes such Crohn's deases. In this study we investigated the hypothesis that subclinical $\mathrm{Zn}$ deficiencies, might lead to increased susceptibility of intestinal epithelial cells to toxic insults and/or inflammation. We investigated the effect of marginal $\mathrm{Zn}$ deprivation on the response of intestinal cells to the inflammatory cytokine TNF $\alpha$. The same model was applied to study the effect of $\mathrm{Zn}$ status on the response of intestinal cells ochratoxin A (OTA), a harmful mycotoxin frequently contaminating a variety of foods. Zn-depleted or Zn-adequate Caco-2 cells were treated with TNF $\alpha$ or OTA. Marginal Zn deprivation makes intestinal cells sensitive to TNF $\alpha$. While TJ integrity was unaffected after $8 \mathrm{~h}$ exposure to TNF $\alpha$ in $\mathrm{Zn}$-adequate cells, $\mathrm{Zn}$ depletion caused a consistent increase of TJ permeability. Massive apoptosis was also observed. A gene expression analysis showed that a number of genes where modulated: the Inhibitor of Apoptosis cIAP2 up-regulation induced by TNF $\alpha$ was dependent by the integrity of $\mathrm{Zn}$ intracellular stores. The oncogene ErbB2 was downregulated by $\mathrm{Zn}$ depletion, especially in the presence of $\mathrm{TNF} \alpha$. Those results indicated that marginal $\mathrm{Zn}$ depletion caused intestinal cell response to TNF $\alpha$ to shift from survival to apoptosis with a mechanism that includes modulation of the expression of genes with key function in signal transduction pathway trigged by $\mathrm{TNF} \alpha$ receptor. Intestinal cells are relatively resistant to high concentrations of OTA, $\mathrm{Zn}$ depletion of cells caused an increase of tight junction permeability in OTA treated cells, accompanied by increased apoptosis. A complex perturbation of $\mathrm{Zn}$ homeostasis was also demonstrated. Our results support the evidences that $\mathrm{Zn}$ has an anti-apoptotic function in intestinal cells and it is able to protect intestinal cells from OTA injury and inflammatory mediators. This suggests that imbalance in $\mathrm{Zn}$ transport and homeostasis, and/or Zn nutritional deficiencies could increase intestinal epithelial susceptibility to toxic insults.

Work supported by grant NUME (DM 3688/7303/08) from the Italian Ministry of Agriculture, Food \& Forestry (MiPAAF). 


\title{
Comparison of butyrate uptake by two non-transformed intestinal epithelial cell lines
}

\author{
Pedro Gonçalves, João R Araújo, Fátima Martel
}

Department of Biochemistry (U38-FCT), Faculty of Medicine, University of Porto, Porto, Portugal

The aim of this study was to characterize the apical uptake of BT by two distinct non-transformed intestinal epithelial cell lines, namely the rat small intestinal epithelial cell line (IEC-6 cells) and the human fetal epithelial colon cell line (FHC cells). Apical uptake of ${ }^{14} \mathrm{C}-\mathrm{BT}(20 \mu \mathrm{M})$ by $\mathrm{FHC}$ cells was: (1) time-dependent, (2) concentration-dependent, with a $\mathrm{K}_{\mathrm{m}}$ of $1.22 \pm 0.45 \mathrm{mM}$ and a $\mathrm{V}_{\max }$ of $109 \pm 17 \mu \mathrm{mol} / \mathrm{mg} \mathrm{prot} / 3 \mathrm{~min}$, (3) $\mathrm{pH}$ independent, (4) $\mathrm{Na}^{+}$- and $\mathrm{Cl}^{-}$-independent, (5) energy-independent, (6) not inhibited by several BT structural analogues (propionate, $\alpha$-ketobutyrate and lactate), and (7) insensitive to monocarboxylate transport (MCT1) inhibitors (NPPB and pCMB). These characteristics suggest a lack of involvement of MCT1-mediated transport in the uptake of ${ }^{14} \mathrm{C}-\mathrm{BT}$. Apical uptake of ${ }^{14} \mathrm{C}-\mathrm{BT}(10 \mu \mathrm{M})$ by IEC-6 cells was: (1) time-dependent, (2) concentration-dependent, with a $\mathrm{K}_{\mathrm{m}}$ of $4.01 \pm 1.1 \mathrm{mM}$ and a $\mathrm{V}_{\max }$ of $70 \pm 14 \mu \mathrm{mol} / \mathrm{mg} \mathrm{prot} / 3 \mathrm{~min}$, (3) $\mathrm{pH}$ dependent, being strongly stimulated at an acidic $\mathrm{pH}$, (4) $\mathrm{Na}^{+}-$and $\mathrm{Cl}^{-}$-dependent, (5) energy-dependent, (6) inhibited by several BT structural analogues (propionate, $\alpha$-ketobutyrate, acetate, pyruvate and lactate), and (7) sensitive to MCT1 inhibitors (NPPB and $\mathrm{pCMB}$ ). These characteristics are compatible with the involvement of $\mathrm{MCT} 1$, and possibly also of the sodium-dependent monocarboxylate transporter 1 (SMCT1), in ${ }^{14} \mathrm{C}-\mathrm{BT}$ uptake. In conclusion, apical uptake of ${ }^{14} \mathrm{C}-\mathrm{BT}$ by $\mathrm{FHC}$ and IEC-6 cells shows rather distinct characteristics. Moreover, comparison of the absolute amount of ${ }^{14} \mathrm{C}-\mathrm{BT}$ taken up by FHC and IEC-6 shows that the former cell line has a very limited capacity to take up BT.

Supported by Fundação para a Ciência e a Tecnologia (FCT) and Programa Ciência, Tecnologia e Inovação do Quadro Comunitário de Apoio (PTDC/SAU-FCF/67805/2006). 


\title{
The effect of folate status on the uptake of physiologically relevant compounds by Caco-
} 2 cells

\author{
Sandra Tavares ${ }^{\mathrm{a}}$, Joana Sousa ${ }^{\mathrm{a}}$, Pedro Gonçalves ${ }^{\mathrm{a}}$, João R Araújo ${ }^{\mathrm{a}}$, M João Pinho ${ }^{\mathrm{b}}$, Fátima Martel ${ }^{\mathrm{a}}$ \\ ${ }^{a}$ Department of Biochemistry (U38-FCT), ${ }^{b}$ Institute of Pharmacology and Therapeutics (U38-FCT), Faculty of Medicine, University of Porto, \\ Porto, Portugal
}

The aim of this work was to investigate the effect of folate status on the uptake of several physiologically relevant substances by Caco-2 cells. For this, Caco-2 cells cultured in high-folate conditions (HF) were compared with cells cultured in low-folate conditions (LF). Growth rates of HF and LF Caco-2 cells were similar. However, proliferation rate of LF cells was significantly greater than that of HF cells during the first two days of culture and slightly smaller thereafter, viability of LF cells was greater than that of HF cells, and apoptosis index was similar in both cell cultures. We verified that in LF cells, comparatively to HF cells: (1) uptake of ${ }^{3} \mathrm{H}$-folic acid was upregulated, via a significant increase in the $\mathrm{V}_{\max }$ of uptake; (2) uptake of ${ }^{3} \mathrm{H}$-deoxyglucose, ${ }^{3} \mathrm{H}$-O-methyl-glucose and ${ }^{3} \mathrm{H}-1$-methyl-4-phenylpyridinium $\left(\mathrm{MPP}^{+}\right)$was downregulated, via a decrease in the $\mathrm{V}_{\max }$ of uptake; additionally, a reduction in $\mathrm{K}_{\mathrm{m}}$ was observed for ${ }^{3} \mathrm{H}$-O-methyl-glucose; (3) uptake of ${ }^{3} \mathrm{H}-5$ hydroxytryptamine and ${ }^{14} \mathrm{C}$-butyrate was not changed; (4) the steady-state mRNA levels of the folic acid transporters RFC, PCFT and FR $\alpha$, of the organic cation transporter OCT1, of the glucose transporter GLUT2 and of the butyrate transporter MCT1 were significantly decreased.

In conclusion, folate deficiency produces substrate-specific changes in the uptake of bioactive compounds by Caco-2 cells (folic acid uptake is upregulated, glucose and organic cation $\left(\mathrm{MPP}^{+}\right.$) uptake is downregulated, and butyrate and 5-hydroxytryptamine uptake are not changed). Moreover, these changes are associated with alterations in the steady-state mRNA levels of specific transporters for these compounds.

Supported by Fundação para a Ciência e a Tecnologia (FCT) and Programa Ciência, Tecnologia e Inovação do Quadro Comunitário de Apoio (PTDC/SAU-FCF/67805/2006). 


\section{REGULATION OF NUTRIENT TRANSPORT}

\section{The regulation of intestinal iron transport by leptin}

Bomee Chun, Paul Sharp

King's College London, Nutritional Sciences Division, London UK.

Obesity is associated with an increase in the production and release of a cocktail of pro-inflammatory cytokines from adipose tissue. In many obese subjects this low-grade inflammatory response leads to poor iron status or anaemia. Iron homeostasis is controlled by the liver-expressed iron regulatory peptide hepcidin. In anaemia of chronic inflammation, cytokine release leads to increased production of hepcidin, which in turn restricts intestinal iron absorption and iron release from reticulo-endothelial macrophages. Here we have focused on the role of leptin in controlling iron homeostasis. Leptin induces hepcidin expression (Chung et al J Nutr 2007 137:2366-70) and we have therefore investigated whether the leptin-hepcidin pathway influences intestinal iron absorption. In addition we explored the possibility that leptin might act directly on intestinal epithelial cells to regulate iron transport.

Studies were performed using Caco-2 cells grown on Transwell inserts and either co-cultured with $\mathrm{HuH} 7$ hepatoma cells pre-stimulated with leptin to produce hepcidin, or mono-cultured in the presence or absence of human recombinant leptin. Iron transporter (DMT1 and FPN) expression was determined by western blotting. The effects of leptin on intestinal iron transport were measured using ${ }^{59} \mathrm{Fe}$. Statistical analyses were performed using Student's unpaired t-test or 1-way ANOVA.

In the $\mathrm{Caco}-2 / \mathrm{HuH} 7$ co-culture system, the leptin-hepcidin axis resulted in a significant decrease in DMT1 protein expression $(\mathrm{P}>0.05)$. We have previously shown that hepcidin decreases Caco-2 cell DMT1 expression and reduces iron transport (Chung et al J Nutr 2009 139:1457-62). Therefore to determine whether leptin directly influenced iron transport, recombinant leptin was added to the basal medium of Caco-2 cell monocultures. Leptin treatment resulted in a significant decrease in both DMT1 $(\mathrm{P}>0.01)$ and FPN $(\mathrm{P}>0.001)$ protein expression and an associated significant decrease in intestinal iron transport $(\mathrm{P}>0.05)$. Taken together our data suggest that leptin can regulate iron homeostasis both directly via its actions on intestinal enterocytes and indirectly via the release of hepcidin from the liver. 


\section{Impaired GLUT2 trafficking in enterocytes of human obese subjects and fat-fed mice.}

Amal Ait Omar ${ }^{\mathrm{a}}$, Maude Le Gall ${ }^{\mathrm{a}}$, Christine Poitou ${ }^{\mathrm{b}, \mathrm{c}}$, Milena Monteiro-Sepulveda ${ }^{\mathrm{a}}$, Anne Houllier ${ }^{\mathrm{a}}$, Danièle Château $^{\mathrm{a}}$, Nicolas Veyrie ${ }^{\mathrm{b}, \mathrm{d}}$, Danielle Hugol ${ }^{\mathrm{e}}$, Joan Tordjman ${ }^{\mathrm{b}}$, Patricia Serradas ${ }^{\mathrm{a}}$, Karine Clément $^{\mathrm{b}, \mathrm{c}}$, Armelle Leturque $^{\mathrm{a}}$, Edith Brot-Laroche ${ }^{\mathrm{a}}$

Centre de Recherche des Cordeliers, ${ }^{a}$ UMRS872 Team 9, ${ }^{b}$ UMRS872 Team 7, ${ }^{c}$ Pitié Salpétière Nutrition and obesity department and ${ }^{d}$ Surgery department and ${ }^{e}$ Pathology department of Hotel Dieu Hospitals, Paris, France

In healthy rodents, the transient insertion of GLUT2 into enterocyte apical membranes accelerates intestinal sugar absorption while insulin resistance associates with permanent apical GLUT2 and increases sugar absorption. Our objective was to establish the relevance of apical GLUT2 as a marker for insulin resistance and obesity in human intestine. Immunofluorescence and electron microscopy studies of human and mouse GLUT2 were performed as well as Western blots of purified intestinal apical membranes. Furthermore iodixanol density gradients were made to decipher the membrane distribution of GLUT2 in cell membranes. Mice models of highfat-low-carbohydrate dietary consumption and of metformin treatment were investigated. In jejunal samples from morbidly obese subjects undergoing bypass surgery, GLUT2 was present in apical and basolateral membranes of enterocytes whereas apical GLUT2 was absent in lean subjects. Diabetes, in morbid obesity did not further modify GLUT2 location. Interestingly, GLUT2 was often found in the enterocytes endosomes of obese subjects eating unbalanced high-fat, low-carbohydrate diets. Mouse models indicated that a prolonged unbalanced fat diet promoted endosomal accumulation of GLUT2 in wild-type mice. It also showed that improvement of glucose homeostasis by metformin treatment could not prevent the accumulation of apical GLUT2 in obese, insulin resistant ob/ob mice. The apical location of GLUT2 is now demonstrated in human intestine. Profound alterations of GLUT2 locations found in enterocyte membranes of insulin resistant obese subjects were consistent with altered capacities for sugar absorption revealed in mice. Apical GLUT2 is thus a marker for intestinal insulin resistance and could constitute a potential target to control intestinal glucose absorption and homeostasis. 


\section{Transport and metabolism revisited: a novel tryptophan transporter in cells expressing} indoleamine and 2, 3 dioxygenase.

\section{Richard Boyd}

Department of Physiology, Anatomy and Genetics, Le Gros Clark Building, University of Oxford, South Parks Road, Oxford OXI 3QX United Kingdom

The explosion of knowledge of both the molecular basis for transport of amino acids and the realisation that there remain many "orphan transporters" still looking for the discovery of their physiological substrates is set out very clearly in the most recent SLC database (http://www.bioparadigms.org/slc/intro.htm). In parallel there has been renewed interest in intracellular metabolism of amino acids exemplified by the discovery of biological consequences of amino acid depletion locally (as in the synaptic cleft for glutamate) and of metabolite production (as for nitric oxide synthesis from arginine). For these integrated biological effects, transport and metabolism must be coupled. However there has to date been little interest in mechanistic aspects allowing coupling of transport and metabolism at a molecular level. Recent studies (Silk et al, Keystone meeting Feb 2010) show how a novel tryptophan transporter has been identified following induction of intracellular IDO activity either by exogenous gene transfection or following endogenous enzyme induction expression by cytokines. The properties of the new system show it to be different from classical system L. Ongoing studies using microarray maybe useful in identifying candidate molecules. This work supports and builds on previous studies (Kudo \& Boyd JPhysiol 2001) in suggesting that the rate limiting step for depletion of extracellular tryptophan in both epithelial and other cell types maybe transport rather than metabolism. It maybe of interest that arginine transporters of the SLC7 family have been shown to have expression that is activated following Tcell stimulation (Crawford \& Boyd Pflugers Arch 1992) and that very recent studies (De Santo et al 2008) show intracellular arginase in such cells suppresses T-cell proliferation. The signalling events, the enzymes and the induced transporters are plausible targets for therapeutic intervention in a wide variety of inflammatory, auto immune and malignant states. 


\section{Functional characterisation of human Proton Amino Acid Transporter 4 (hPAT4) expressed in Xenopus oocytes}

Samyuktha Muralidharan Pillai, David Meredith

School of Life Sciences, Oxford Brookes University, Oxford OX3 OBP, UK.

The membrane transporter-mediated movement of amino acids across biological membranes is an indispensible step in their absorption and metabolism. One such family are the Proton-coupled Amino acid Transporters (SLC36 family), which in humans consists of 4 members, hPATs 1-4 (SLC36A1-A4, respectively; Boll et al. 2004, Pflügers Archiv). PAT1 and PAT2 have been characterised to be $\mathrm{H}^{+}$-coupled $\mathrm{Na}^{+}$-independent amino acid transporters having maximum uptake at pH 5.5 (reviewed by Thwaites \& Anderson 2007, Exp Physiol). Mutations in PAT2 have recently been identified as responsible for iminoglycinuria, a hereditary disease where the defect is in absorption of proline and glycine (Broer et al. 2008, J Clin Invest). PAT3 and PAT4 are 'orphan transporters' whose function to date had not been established. To investigate the functional characteristics of hPAT4, capped mRNA was synthesised In vitro using the linearised PAT4 clone (IMAGE 5313230) which had been sub-cloned into a vector optimised for expression in Xenopus oocytes. hPAT4 mRNA was then injected into Xenopus oocytes, and following 72 hours incubation to allow protein expression, transport assays were performed using $\left[{ }^{3} \mathrm{H}\right]$-proline using a similar approach to that previously described (Goberdhan et al. 2005, Development). Our results show that PAT4 mediated uptake of proline with transport activity highest with an extracellular $\mathrm{pH}\left(\mathrm{pH}_{\text {out }}\right)$ of 7.4, whereas at $\mathrm{pH}_{\text {out }} 5.5$ uptake was reduced by over 2.5 -fold to very low levels. No current could be measured in hPAT4 expressing oocytes in the presence of proline compared to controls. In comparison, hPATs 1 and 2 both show maximal uptake at $\mathrm{pH}_{\text {out }} 5.5$ and are electrogenic (proton-coupled). PAT4 is also $\mathrm{Na}^{+}$-independent like the other members of the SLC36 family. Kinetically, hPAT4 has a very high affinity for proline (Ki $3.13 \pm 1.13 \mu \mathrm{M}, \mathrm{n}=3$ oocyte preparations), and shows a different range of transported and nontransported amino acid substrates to the previously characterised hPAT1 and 2. In conclusion we have demonstrated that hPAT4 is a very high affinity amino acid transporter, whose characteristics and physiological role require further investigation. 


\section{Transport of some disaccharides in rat and human small intestine. The enzyme- transport complex really exists}

Sergey T Metelsky

Institute of general pathology and pathophysiology RAMS, Moscow, Russia

Background. A. Ugolev (Ugolev, 1989) suggested that membrane hydrolysis and transport of some oligomers of nutrients are performed by enzyme-transport complexes (ETC). Such complex would work effectively if the released monomers are transferred to the transporter input without appearing in the surrounding solution.

Aim. To compare the properties of enzyme-transport complexes for the disaccharide maltose (glucose + glucose) with those of $\mathrm{Na}^{+}$-dependent transporter for glucose in rats and humans.

Methods. In isolated samples of the rat $(\mathrm{n}=85)$ and human $(\mathrm{n}=19)$ small intestine we recorded the pairs of successive responses of the short-circuit current (SCC) to the addition of maltose and glucose to the washing solution. Maltose and glucose were added in the ratio 1:2 (by concentration). The magnitude of the SCC response on sugar characterizes the rate of $\mathrm{Na}^{+}$-dependent transport of this molecule.

Results. In rats, SCC responses to $5 \mathrm{mM}$ maltose and $10 \mathrm{mM}$ glucose under a wide range of experimental conditions were practically equal. The correlation coefficient was equal to 0.992 , the linear regression equation $\mathrm{Y}=0.1+1.05 * \mathrm{X}$. Disaccharide cellobiose (glucose + glucose, bond by another type of link than that in maltose) non-hydrolyzed in rat intestine, did not stimulate the SCC. The stimulating effect of $10 \mathrm{mM}$ of poorly hydrolyzed in adult rats lactose (glucose + galactose) was much smaller than effects of simultaneous addition of $10 \mathrm{mM}$ glucose $+10 \mathrm{mM}$ galactose or $20 \mathrm{mM}$ glucose to mucosal solution. Comparing the dynamics of sugars diffusion through unstirred layer to brush border membrane with the dynamics of the SCC response to the addition of maltose and glucose one can conclude that glucose derived from maltose molecules apparently did not appear in the surrounding solution. Data obtained on the human small intestine indicate that the ratio of the SCC responses on $5 \mathrm{mM}$ maltose and $10 \mathrm{mM}$ glucose may be either less or more than 1.0. Correlation coefficient was equal to 0.551 .

Conclusion. In humans, the enzyme-transport complex for maltose transport probably does not exist. On the contrary in rats, $\mathrm{Na}^{+}$-dependent transport of maltose and glucose shares the same mechanism - the enzymetransport complex. 


\title{
Chloroplast thylakoid membranes retard intestinal uptake of glucose
}

\author{
$\mathrm{C}$ Montelius $^{a}, \mathrm{~K}$ Gustafsson $^{a}, \mathrm{P} \AA$ Albertsson $^{b}, \mathrm{~B}$ Weström $^{c}, \mathrm{C}$ Erlanson-Albertsson ${ }^{a}$ \\ ${ }^{a}$ Dept of Experimental Medical Science, BMC, ${ }^{b}$ Dept of Biochemistry, Chemical Centre, ${ }^{c}$ Dept of Biology, Lund University, Lund, Sweden
}

Hyperglycemia is a major symptom in non-insulin dependent diabetes, the most prevalent disease affecting individuals with a Westernized life style. Management of hyperglycemia relies mainly on reduction of dietary carbohydrate intake, the use of low-glycemic, instead of high-glycemic, carbohydrates or the use of hypoglycemic agents that stimulate uptake of glucose from the blood into peripheral cells. However, control of the intestinal absorption of glucose would help to improve levels of glucose and has until now not been exploited. In previous work we have demonstrated a reduction of blood glucose after oral administration of thylakoids, chloroplast membranes that retard fat digestion and promote satiety. We now show that thylakoids reduce the intestinal uptake of glucose using an in vitro model of intestinal passage. Intestinal segments dissected from rats were mounted in Ussing chambers with modified Krebs buffer containing glucose, oleic acid and NaTDC. Methyl- $\left[{ }^{3} \mathrm{H}\right]$-D-glucose, FITC-dextran $(4 \mathrm{kD})$ and ovalbumin $(45 \mathrm{kD})$ were added as markers on the mucosal side together with different concentrations of thylakoids (isolated from spinach leaves) and the marker passage was measured on the serosal side. A dose-dependent reduction of passage of glucose was observed in the presence of thylakoids. In addition, the passage of the macromolecular markers, dextran and ovalbumin, was decreased by the thylakoids. Using electron microscopy, the thylakoids were demonstrated as circular structures absorbed to the intestinal epithelium. This is the first time biological membranes have been shown to influence the transport of molecules over the intestinal wall. We suggest that the ability of the thylakoids to decrease the intestinal passage of molecules may be important both to control postprandial hyperglycemia as well as to improve intestinal barrier properties during, e.g., inflammatory conditions. 
Transport studies in human intestinal Caco-2 cells under optimized culture conditions using serum-free medium.

\author{
Yula Sambuy ${ }^{\mathrm{a}}$, Simonetta Ferruzza ${ }^{\mathrm{a}}$, Carlotta Rossi ${ }^{\mathrm{a}}$, Mirjam Spansier ${ }^{\mathrm{b}}$, Manuela Natoli ${ }^{\mathrm{c}}$, Maria Laura Scarino ${ }^{\mathrm{a}}$. \\ ${ }^{a}$ National Research Institute on Food and Nutrition (INRAN) - Rome, Italy, ${ }^{b}$ Merck Research Laboratories - Oss, The Netherlands, ${ }^{\mathrm{c}}$ Institute \\ of Neurobiology and Molecular Medicine (INMM), Rome, Italy
}

The human intestinal Caco-2 cell line represents the best available model for studies of intestinal transport, metabolism and toxicity, and has been extensively used for over two decades in laboratories all over the world. However, several reports in the literature point to great heterogeneity and variability in the expression of differentiated functions in this experimental model that can largely be ascribed to differences in culture procedures. Addition of foetal bovine serum (FBS) in the culture medium represents a source of variability in the performance of the Caco-2 cell line. We have been investigating different protocols to achieve optimal differentiation of Caco-2 cells in the absence of the serum supplement. In particular, permeability properties and transport by the apical carriers Pgp and PepT1 have been investigated in cells differentiated for up to 21 days on polycarbonate filter inserts in medium supplemented with different serum substitutes in the basolateral medium. These included insulin, transferrin and selenium (ITS) supplemented with a lipid mixture made of oleate, palmitate and cholesterol (ITS/Lipids) or $\mathrm{MITO}^{\circ}{ }^{\circ}$ Serum Extender, a commercial mixture of hormones and growth factors, with or without addition of the lipid mixture. The active transports of cephalexin (by PepT1) and of digoxin (by Pgp) in cells differentiated in the presence of MITO+ were expressed to the same or even higher levels than those of control cells differentiated in the presence of serum. Permeability to mannitol was unaffected in all conditions of serum-free medium, indicating functional closure of the tight junctions, although the presence of the MITO+ supplement resulted in lower TEER values, in line with the lower electrical resistance of the small intestinal epithelium compared to the colon.

Several laboratories still utilize an impermeable plastic substrate instead of permeable filter supports to differentiate Caco-2 cells, especially when accessibility to the basolateral membrane is not required (i.e. for gene expression, intracellular metabolism, apical activities or uptake studies). We therefore investigated the effects of plastic or filter substrates on the differentiation properties of Caco-2 cells. Our results indicate that gene expression, enzyme activities, morphology and protein localization are strongly affected by the nature of the substrate and that an impermeable substrate such as plastic does not allow full and homogeneous differentiation of the cell monolayer.

Work supported by EU FP6 Project "LIINTOP” Contract number STREP-037499. 


\section{The efficiency of coupling between hydrolysis of oligosaccharides and absorption of glucose in the small intestine in vivo}

Andrei Gruzdkov ${ }^{\mathrm{a}}$, Liudmila Gromova ${ }^{\mathrm{a}}$, Nadezhda Grefner ${ }^{\mathrm{b}}$, Yan Komissarchik ${ }^{\mathrm{b}}$

${ }^{a}$ I.P.Pavlov Institute of Physiology, RAS, ${ }^{b}$ Institute of Cytology, RAS, St.-Petersburg, Russia

The rates of maltose and maltotriose hydrolysis, and glucose (free one, and released from oligosaccharides) and water absorption in isolated loop of the rat small intestine were determined during a sequential perfusion of the loop $(\sim 18 \mathrm{~cm})$ with solutions of the substrates in equivalent concentrations under conditions of chronic experiments. By means of immunofluorescent analysis, the distribution of glucose transporters SGLT1 and GLUT2 in the enterocytes was investigated at various levels of intestinal villi, and at low (25 $\mathrm{mM}$ ) and high $(200 \mathrm{mM})$ glucose loads. The coupling coefficient (a ratio of the rate of released glucose absorption to the rate of oligosaccharide hydrolysis) proved to be the highest (0.783) under perfusion of the loop at the rate of $0.26 \mathrm{ml}$ per min with maltotriose solution $(66.6 \mathrm{mM})$. In all experiments, rates of free glucose (G-glucose) absorption did not differ significantly from the rates of M- and MT-glucose absorption from equivalent maltose and maltotriose solutions, respectively. Rates of water absorption from the loop were significantly higher under perfusion of the loop with maltose $(100 \mathrm{mM})$, and maltotriose $(66.6 \mathrm{mM})$ solutions as compared with those under perfusion with equivalent glucose solutions. The distribution of SGLT1 and GLUT2 in the enterocytes of intestinal villi was different at low and high glucose loads. The transporters were visualized in the villus upper one-third at low glucose load and in total length of the villus at high glucose load. A mathematical model has been developed which takes into account the geometric peculiarities of the small intestinal absorptive surface, and A.M. Ugolev's hypothesis that the affinity of glucose, just released from oligosaccharides, is higher than that of free glucose. Results of simulation are in a good accordance with the corresponding experimental data. The model predicts that under physiological conditions a transfer of the substrates across the pre-epithelial layer via solvent drag plays a minor role as compared with their diffusion across this layer.

Supported by the Russian Foundation for Basic Research (grant No 08-04-00675). 


\section{Characterization of the human glucose cotransporter GLUT12}

\section{Alejandra Pérez $z^{\mathrm{a}}$, Jonai Pujol ${ }^{\mathrm{b}}$, Asunción Redín ${ }^{\mathrm{b}}$, Alejandro Reyes ${ }^{\mathrm{a}}$, M. Pilar Lostao ${ }^{\mathrm{b}}$}

${ }^{a}$ Department of Biochemistry, Austral University of Chile, Valdivia, Chile. ${ }^{b}$ Department of Physiology, Toxicology and Nutrition, University of Navarra, Pamplona 31008, Spain.

The facilitative glucose transporters GLUT/SLC2A are integral membrane proteins widely distributed in mammalian cells. Until now fourteen isoforms have been identified, which have been subdivided into three different classes (I, II and III) based on the amino acid sequences. In the present work, we have cloned GLUT12 (class III) from the mammary cancer cell line MCF7 and studied its kinetic characteristics and sensitivity for classical GLUT transporters inhibitors, still unknown. GLUT12 was expressed in Xenopus laevis oocytes and kinetic parameters were obtained using uptake assays. Selectivity for inhibitors was studied on transfected MDCK cells. The studies were performed in sodium buffer at $\mathrm{pH}$ 7,5. 3-O-methyl-D-glucose showed a $\mathrm{K}_{0.5}$ of $5 \mathrm{mM}$ and $\mathrm{V}_{\max }$ of 24 pmoles/oocyte/min. In the absence of $\mathrm{Na}^{+}$the sugar uptake was decreased by $50 \%$, which suggested the possibility of cotransport activity for GLUT12. Preliminary electrophysiological experiments in oocytes expressing the transporter demonstrated the presence of $\mathrm{Na}^{+}$currents at saturating sugar concentrations. The inhibition studies performed in transfected cells showed sensitivity of GLUT12 to cytochalasin B and inhibitors of GLUT1 like genistein, quercetin and tyrphostin A47. Based on these results, we suggest that GLUT12 could function as a cotransporter like the $\mathrm{H}^{+}$/myoinositol transporter, which also belongs to class III. Work in progress will allow us to characterize more deeply this transporter.

This work was supported by Fundación Marcelino Botin and Ministerio de Ciencia y Tecnología (Spanish Government) Grant BFU2007-60420. The Spanish group is member of the Network for Cooperative Research on Membrane Transport Proteins (REIT), co-funded by the Ministerio de Educación y Ciencia, Spain and the European Regional Development Fund (ERDF) (Grant BFU2007-30688-E/BFI). 
The absorption of glucose and the localization of SGLT1 and GLUT2 in Caco-2 cells at different glucose loads

\author{
Nadezhda Grefner ${ }^{\mathrm{a}}$ Liudmila Gromova $^{\mathrm{b}}$, Andrei Gruzdkov ${ }^{\mathrm{b}}$, Yan Komissarchik ${ }^{\mathrm{a}}$ \\ ${ }^{a}$ Institute of Cytology, RAS, ${ }^{b}$ I.P.Pavlov Institute of Physiology, RAS, St.-Petersburg, Russia
}

Many studies have demonstrated $\mathrm{Na}^{+}$-dependent glucose transport in Caco-2 cells. However, it remains unclear whether a facilitated diffusion, mediated by GLUT2, participates in glucose uptake by these cells at high substrate loadings, as is the case in enterocytes of the small intestine. The aim of this study was to compare the localization of glucose transporters SGLT1 and GLUT2 in Caco-2 cells during glucose absorption at low and high concentrations of substrates. The Caco-2 cells (on the $21^{\text {st }}$ day) were incubated for three hours in glucose $(2.5$ and $25.0 \mathrm{mM})$, as well as in the same solutions in the presence of phloridzin $(0.1 \mathrm{mM})$. The cultured cells, incubated in a buffer solution without substrates, served as controls. Glucose absorption was determined by a decrease of its concentration in the incubation medium. To identify actin, the cells were stained by rhodamine phalloidin. The glucose transporters were visualized using immunofluorescent staining. The preparations were viewed on confocal microscope Leica TCS SL. Glucose absorption, observed during incubation of the cultured Caco-2 cells in glucose solutions, was inhibited by phloridzin. Electron microscopy analysis had shown that the cells, cultured during 21 days, formed a confluent monolayer with all intercellular junctions, had a polarized structure and the brush border. A label for SGLT1 transporter was detected with similar intensities in the apical, lateral and basal parts of the cellular cytoplasm, both in the control, and at different glucose loads. In the control and the case of glucose load in presence of phloridzin, a label for GLUT2 was found both in the apical and basal parts of cytoplasm. In cultures incubated in a solution of glucose $(2.5 \mathrm{mM})$, a label for GLUT2 was detected mainly in the basal cytoplasm of the cells, whereas in the case of glucose $25 \mathrm{mM}$, the label mainly appeared in the apical region of cytoplasm, being co-localized with actin in terminal web and in the microvilli. These results suggest that at low carbohydrate loads the glucose absorption in Caco-2 cells occurs via the $\mathrm{Na}^{+}$-dependent active transport. At high carbohydrate loads, along with the $\mathrm{Na}^{+}$-dependent active transport, a facilitated diffusion, mediated by the apical GLUT2, is also involved in the absorption of glucose. Active transport of glucose apparently triggers the transfer of glucose across the apical membrane by GLUT2. 


\section{Leptin and insulin control the activity and expression of intestinal hexose transporter} SLC2A7/GLUT7

Sakar Yassine, Nazaret Corinne, Bado André, Ducroc Robert

Physiologie et Neuroendocrinologie Digestive, Inserm U773, CRB3, Paris, France

GLUT7 (SCL2A7) is a new facilitated hexose transporter that has been primarily identified in the intestine ( $\mathrm{Li}$ et al 2004). This transporter exhibits high affinity for fructose and glucose in vitro. The regulation of expression/activity of this GLUT7 transporter is currently unknown. Here we address this question by studying the effects of leptin and insulin, two distinct regulators of GLUTs activity.

Methods: Wistar rats and C57BL/6J mice were used after a 16-hour food deprivation period. Under anaesthesia, jejunal loops were isolated in situ and were randomly pre-treated 3 min with intraluminal $1 \mathrm{nM}$ leptin. Thereafter the loops were challenged with either $30 \mathrm{mM}$ fructose or $30 \mathrm{mM}$ glucose. Insulin (1 UI/ $\mathrm{kg})$ was given i.p $3 \mathrm{~min}$ after sugars. After $5 \mathrm{~min}$ or $3 \mathrm{hrs}$, brush-border membranes (BBM) or total RNA were extracted from mucosa scrapings for western blot analysis of GLUT7 protein (antibody ABIN154302) or quantitative PCR of GLUT7 mRNA levels, respectively.

Results: In the isolated rat jejunal loops, glucose or fructose added into the lumen significantly increased the GLUT7 protein in BBM by 1.5 fold and 1.25 respectively compared to control. Luminal leptin alone significantly increased and i.p insulin significantly decreased the GLUT7 abundance in BBM. A combination of leptin with glucose or fructose gave GLUT7 levels of 2.0- and 1.9 fold higher amounts than those observed in controls, $(\mathrm{P}<0.05)$. Finally, in the mice in vivo oral leptin significantly increased $(+23 \%)$ the GLUT7mRNA levels compared to control.

Conclusion: This is the first demonstration that the new hexose transporter GLUT7 is controlled by the gut leptin and pancreatic insulin. This suggests that GLUT7 is functionally involved in the regulation of hexose transport during a meal. 
'Junk-food' diet-induced obesity has different effects on glucose transporters in the kidney and jejunal brush border membrane

Havovi Chichger, Marie Houdmont, Johanne Marks, Scott Wildman, Edward S Debnama , Robert J Unwin.

London Epithelial Group, University College London, London, UK; Royal Veterinary College, London, UK

The epidemic of obesity that has developed in the last 20 years is thought to be largely diet-related, and it is associated with a range of clinical disorders, including hypertension and type II diabetes. Diabetic hyperglycaemia in rats induces expression of GLUT2 at the proximal tubule (PT) brush border membrane (BBM); levels of GLUT2 show a positive correlation with plasma glucose level (PGL) and expression of PKC$\beta \mathrm{I}$ at the PT BBM. GLUT2 expression at jejunal BBM also increases in conditions of high PGL or high luminal glucose, and this can occur within minutes. Moreover, intestinal expression of GLUT2 is regulated by SGLT1mediated glucose uptake and PKC-BII signalling. Our present study has examined the effect of feeding a junkfood (JF) diet on expression of glucose transporters at the renal and jejunal BBM. Wistar rats were given ad libitum access to chow, with or without palatable processed junk food, rich in energy, fat, sugar and salt. After 8 weeks, renal and jejunal BBM vesicles were prepared for western blotting.

JF fed animals displayed a preference for junk-food over chow; animals consumed similar amounts of food (20.8 $\pm 0.6 \mathrm{~g}$ junk-food/day) as controls fed chow-fed alone ( $20 \pm 0.2 \mathrm{~g} /$ day $)$. JF fed rats were $40 \%$ heavier than chow-fed rats $(\mathrm{p}<0.005)$ and were mildly hyperglycaemic $(10.7 \pm 0.4 \mathrm{mM}$ vs $8.53 \pm 0.4 \mathrm{mM}, \mathrm{p}<0.005)$. A significant increase in renal GLUT2 $(576 \%, \mathrm{p}<0.001)$ and its regulator, PKC- $\beta I(71 \%, \mathrm{p}<0.005)$, occurred at the BBM in JF fed animals compared to control-fed animals. In the jejunum BBM, GLUT2 expression was unaffected by JF diet but interestingly SGLT1 expression was significantly decreased $(-108 \%, \mathrm{p}<0.001)$. Our findings highlight the link between a sustained intake of JF diet and glucose handling in the kidney, and reveal differential effects of this diet on glucose transporter expression at the jejunal and renal BBM. 


\section{Molecular characterization of glucose transporter expression in the small intestine of}

\section{broiler chickens after chronic deoxynivalenol exposure}

Wageha Awad ${ }^{\mathrm{a}, \mathrm{b}}$, Wilfried Vahjen ${ }^{\mathrm{a}}$, Jörg R Aschenbach ${ }^{\mathrm{b}}$, Jürgen Zentek ${ }^{\mathrm{a}}$.

${ }^{a}$ Institute of Animal Nutrition, Department of Veterinary Medicine, Free University of Berlin, Germany; ${ }^{b}$ Inst. for Physiology,

Pathophysiology and Biophysics, University of Veterinary Medicine Vienna, Austria

Two types of transporters are involved in the brush border membrane hexose transport in the small intestine of higher organisms: i) facilitated glucose transporters (GLUT-2) and ii) $\mathrm{Na}^{+}$coupled glucose transporters (SGLT-1). The activity of SGLT-1 is regulated by dietary substrate levels in some species. In the present study, mRNA expression of SGLT-1 and GLUT-2 were determined in the chicken small intestine after exposure to deoxynivalenol (DON) because previous studies had shown that intestinal glucose transport is influenced by chronic exposure to deoxynivalenol.

Materials and Methods: Broiler chicken were fed a diet containing 0 (control), 1 or $5 \mathrm{mg} / \mathrm{kg}$ DON. Immediately after slaughter at day 35 , intestinal pieces of the mid-duodenum and mid-jejunum were washed four times in sterile, ice-cold phosphate-buffered saline and immersed in the RNA stabilizing agent, RNA-later (Qiagen, Hilden, Germany). Total RNA was extracted with a commercial extraction kit (RNeasy Protect Mini Kit, Qiagen, Hilden, Germany). RT-PCR was performed using primers for chicken SGLT-1, GLUT-2 and GAPDH. The software REST2005 was used to calculate expression of SGLT-1 and GLUT-2 relative to GAPDH.

Results: The relative expression of SGLT-1 normalized to GAPDH and calibrated to the control group was 0.208 and 0.406 in the duodenal tissue, and 0.197 and 0.134 in the jejunal tissue for both deoxynivalenoltreated groups ( 1 and 5), respectively. The normalized expression of GLUT-2 relative to control animals was 0.384 and 0.657 in the duodenal tissue, and 0.946 and 0.990 in the jejunal tissue for both deoxynivalenol-treated groups (1 and 5), respectively. The results indicated that SGLT-1 was down-regulated in duodenal and jejunal tissues of both trial groups $(\mathrm{P}<0.01)$. GLUT-2 was down-regulated only in duodenal tissues for both DON groups.

Conclusion: DON suppressed the mRNA abundance of intestinal glucose transporters in chicken, implying that DON can indeed alter the expression levels of nutrient transporters. 


\section{Transport of uridine derivates by the rat $\mathrm{Na}^{+} /$nucleoside cotransporter (rCNT2)}

Carlos Sancho ${ }^{a}$, Aitziber Garcés ${ }^{\mathrm{a}}$, Alonso Fernández-Nistal ${ }^{\mathrm{a}}$, Carmen Sanmartín ${ }^{\mathrm{b}}$, Gorka Guereñu ${ }^{\mathrm{a}}$, M.Pilar Lostao $^{\mathrm{a}}$.

${ }^{a}$ Dept. of Nutrition, Food Science, Physiology and Toxicology, University of Navarra, Pamplona 31008, Spain. ${ }^{b}$ Dept. Organic and Pharmaceutical Chemistry, University of Navarra, Pamplona, Spain.

CNT2 is a high affinity $\mathrm{Na}^{+}$/nucleoside cotransporter which transports purine nucleosides, uridine, and nucleoside analogs with therapeutics properties. We previously characterized the rCNT2 function using electrophysiological techniques. In the present work, we have investigated the ability of rCNT2 to transport uridine derivates to obtain more information about the structural requirements of the substrates.

Rat CNT2 was expressed in Xenopus laevis oocytes and kinetic parameters of the derivates were obtained using the two-electrode voltage-clamp technique. Results show that 2'-deoxi-uridine was transported with 6-fold decrease in affinity ( $\mathrm{K}_{0.5}$ of $160 \mu \mathrm{M} v s .24 \mu \mathrm{M}$ for uridine) but with a $\sim 100 \%$ increase in $\mathrm{I}_{\max }$. Halogenated residues in the 5 position of the pyrimidine ring were accepted: $\mathrm{F}$ did not modify the kinetic parameters whereas the increase in the size and diminution in the electronegativity of the substituent (I, Br) highly decreased both affinity and $\mathrm{I}_{\max }$. Other derivatives were synthesized by functionalizing uridine with aromatic systems that were substituted in position 4' (to regulate size and polarity) and bound by aliphatic chains of variable length to the 5 position of the pyrimidine ring. All were well transported with a $\mathrm{K}_{0.5} 2$-fold higher that uridine and a 30-20 reduction in $\% \mathrm{I}_{\max }$ compared with uridine.

Preliminary studies show that human CNT2 also transports the uridine derivatives containing aromatic systems but with $\mathrm{K}_{0.5}$ in the $\mathrm{mM}$ range and a $\sim 3-4$ times higher $\mathrm{I}_{\max }$ compared rCNT2. In summary, rCNT2 is able to transport bulky uridine derivates which suggests a relatively big binding pocket for the substrate.

This work was supported by Fundación Marcelino Botin and Ministerio de Ciencia y Tecnología (Spanish Government) Grant BFI 2003-01371. The group is member of the Network for Cooperative Research on Membrane Transport Proteins (REIT), co-funded by the Ministerio de Educación y Ciencia, Spain and the European Regional Development Fund (ERDF) (Grant BFU2007-30688-E/BFI). 


\section{Interaction of nucleoside-derivatives with human concentrative nucleoside transporters} hCNT1 and hCNT3

Edurne Gorraitz ${ }^{\mathrm{a}}$, Carmen Sanmartin ${ }^{\mathrm{b}}$, Paula Fernández-Calotti ${ }^{\mathrm{c}}$, Marçal Pastor-Anglada ${ }^{\mathrm{c}}$, M Pilar Lostao $^{\mathrm{a}}$.

${ }^{a}$ Dept. of Nutrition, Food Science, Physiology and Toxicology, ${ }^{\mathrm{b}}$ Dept. Organic and Pharmaceutical Chemistry, University of Navarra, Pamplona, Spain, 'Dept. Biochemistry and Molecular Biology, University of Barcelona, CIBER EHD, Barcelona, Spain.

Concentrative nucleoside transporters are membrane proteins involved in anticancer and antiviral nucleoside-derived drugs uptake. Human CNT1 (hCNT1) transports pyrimidine nucleosides and is inhibited by adenosine. Human CNT3 (hCNT3) transports both pyrimidine and purine nucleosides. In the present work, we have synthesized uridine and adenosine derivatives and investigated their interaction with hCNT1 and hCNT3 using the two-electrode voltage clamp technique applied to Xenopus laevis oocytes expressing these transporters. The nucleoside derivatives were synthesized by functionalizing uridine and adenosine with aromatic systems that were substituted in positions 4' and bound by aliphatic chains of variable length.

The uridine derivatives were transported through hCNT1 with similar affinity than uridine $\left(\mathrm{K}_{0.5} \approx 30 \mu \mathrm{M}\right)$ but with a $40-50 \%$ reduction in their maximum transport rate $\left(\mathrm{I}_{\max }\right)$. However, they were transported through hCNT3 with higher affinity than uridine $\left(\mathrm{K}_{0.5} \approx 3-8.6 \mu \mathrm{M}\right)$ and lower $\mathrm{I}_{\max }$. The adenosine-derivatives were inhibitors of hCNT1 with $\mathrm{K}_{\mathrm{i}} 2-5$ times higher than that for adenosine $(6 \mu \mathrm{M})$, but they were transported through hCNT3 with lower affinity than adenosine $(500 v s 18 \mu \mathrm{M})$ and half of its maximal transport rate. Cytotoxicity assays performed in MCF-7 cells showed the lowest $\mathrm{IC}_{50}$ for two of the adenosine derivatives that were in the range 17- $35 \mathrm{mM}$. In summary, both hCNT1 and hCNT3 can transport bulky derivates of uridine and adenosine with similar affinities and maximum transport rates. For hCNT3 modifications in uridine are better tolerated that in adenosine.

This work was supported by Fundación Marcelino Botin and Ministerio de Ciencia y Tecnología (Spanish Government) Grants BFI 2003-01371 and SAF2008-00577. The groups are members of the Network for Cooperative Research on Membrane Transport Proteins (REIT), co-funded by the Ministerio de Educación y Ciencia, Spain and the European Regional Development Fund (ERDF) (Grant BFU2007-30688-E/BFI). 
The inhibitory effect of IL-1b on fructose intestinal transport is related to PKC, PKA and proteasome

Alberto García-Barrios ${ }^{\mathrm{a}, \mathrm{b}}$, Sonia Gascón ${ }^{\mathrm{a}, \mathrm{b}}$, Isabel Escudero ${ }^{\mathrm{b}}$, Natalia Guillén ${ }^{\mathrm{a}, \mathrm{c}}$, Jesús Osada ${ }^{\mathrm{a}, \mathrm{c}}$, M Pilar Lostao $^{\mathrm{d}}$, $M^{a}$ Jesús Rodríguez-Yoldi ${ }^{\text {a,b }}$.

${ }^{a}$ CIBER Fisiopatología de la Obesidad y Nutrición, Instituto de Salud Carlos III, Spain. ${ }^{b}$ Dept. of Pharmacology and Physiology, ${ }^{c}$ Dept. of Biochemistry and Molecular Biology. Veterinary Faculty, University of Zaragoza, Spain. 'Dept. of Nutrition, Food Science, Physiology and Toxicology. Science Faculty, University of Navarra, Spain.

The intestinal absorption epithelium serves as dynamic barrier which, under normal condition, maintains the regulated uptake of nutrients and water while excluding potential pathogens. During intestinal inflammation there is an increase in permeability induced by various inflammatory mediators. The soluble mediators Interleukin $1 \mathrm{~b}$ (IL-1b) is a potent inflammatory cytokine involved in many important cellular functions. Objetives: To determine the effect of IL-1b on fructose intestinal transport and try to identify the intracellular mediators implicated in this process. Methods: A sepsis condition was achieved 90 min after intravenous administration of IL-1b (0.2 mg/kg body weight -b.w.-) in rabbits. D-fructose intestinal transport was studied in brush border membrane vesicles (BBMV) of jejunum from control and IL-1b treated animals. The level of expression of the D-fructose transporter GLUT5 was analyzed by Western blot. Results: In treated animals, the transport of $5 \mathrm{mM}$ D-fructose was reduced while the expression level of GLUT5 was the same in all animal groups. Several inhibitors were i.v. administered 15 min before cytokine injection. The PKA inhibitor IP20 (0.155 mg/kg b.w), PKC inhibitor GF-109203X (500 ng/kg b.w) and proteasome inhibitor MG-132 (250 mg/kg b.w.) abolished the effect of the IL-1b on the sugar transport. Conclussions: D-fructose transport across BBMV is inhibited via a decrease in the relative intrinsic activity of GLUT5 protein. Several intracellular pathways activated during inflammatory processes seem to be implicated, involving PKC, PKA and the proteasome.

This work was supported by grants from FIS and ISCIII CB06/03/1012, Dept. de Ciencia, Tecnologia y Universidad del Gobierno de Aragón (Spain): A-32, PM051/2007and PI017/09, and "Departamento de Educación", Navarra Government, Spain. The group is member of the Network for Cooperative Research on Membrane Transport Proteins (REIT) BFU2007-30688-E/BFI). 


\title{
Apical leptin down-regulates sugar and glutamine apical membrane transporters in
}

\section{Caco-2 cells}

\author{
Carmen Fanjul $^{\mathrm{a}}$, Sakar Yassine ${ }^{\mathrm{b}}$, Robert Ducroc $^{\mathrm{b}}$, Ana Barber ${ }^{\mathrm{a}}$, M. Pilar Lostao ${ }^{\mathrm{a}}$ \\ ${ }^{a}$ Department of Nutrition, Food Science, Physiology and Toxicology, University of Navarra, Pamplona 31008. ${ }^{b}$ Institut National de la Santé \\ et de la Recherche Médicale, Unité 773 ; IFR02 Claude Bernard, Faculté de Médecine Xavier Bichat. 16, rue Henri Huchard, 75890 Paris \\ cedex 18, France
}

In previous works, we demonstrated that leptin inhibits the transport of sugars and amino acids in rat intestine and Caco-2 cells. In continuation with our investigations, the aim of the present work was to study the role of leptin in the post-transcriptional regulation of nutrients transporters in Caco-2 cells. In cells grown on plates, the apical uptake of $0.1 \mathrm{mM} \alpha$-methyl-glucoside, $\alpha \mathrm{MG}$ (substrate of SGLT1), Gln (substrate of ASCT2 and $\mathrm{B}^{0} \mathrm{AT} 1$ ) and Phe (substrate of $\mathrm{B}^{0} \mathrm{AT} 1$ ) was measured in the absence and presence of $8 \mathrm{nM}$ leptin after $30 \mathrm{~min}$ incubation. Besides, the expression of SGLT1, ASCT2 and $\mathrm{B}^{0} \mathrm{AT} 1$ was analyzed by Western blot using brush border membrane vesicles (BBMV), isolated from Caco-2 cells incubated under the same experimental conditions. The uptake of $\alpha \mathrm{MG}$ and Gln was inhibited by apical leptin by $\sim 30 \%$. Western blot analysis showed increase on the expression of SGLT1 and $\mathrm{B}^{0} \mathrm{AT} 1$ in the BBMV after incubation of the cells with the corresponding substrates, and that this increase was reduced by leptin. Although the expression of ASCT2 was not regulated by the substrate, leptin also reduced ASCT2 expression in the presence of Gln. In summary, leptin acting from the apical membrane of Caco-2 cells inhibits the transport of $\alpha \mathrm{MG}$ and Gln by reducing the corresponding transporter levels in the membrane.

This work was supported by Ministerio de Ciencia y Tecnologia (Spanish Government) Grant BFU200760420 and Fundación Marcelino Botin. The Spanish group is member of the Network for Cooperative Research on Membrane Transport Proteins (REIT), co-funded by the Ministerio de Educación y Ciencia, Spain and the European Regional Development Fund (ERDF) (Grant BFU2007-30688-E/BFI). 


\section{Human Monocarboxylate Transporter 9 (MCT9) mediates carnitine efflux when expressed in xenopus oocytes}

David Meredith ${ }^{\mathrm{a}}$, Karsten Suhre ${ }^{\mathrm{b}}$

${ }^{a}$ School of Life Sciences, Oxford Brookes University, Oxford OX3 OBP, UK \& ${ }^{b}$ Institute of Bioinformatics \& Systems Biology, Helmholtz Zentrum Muenchen, German Research Centre for Environmental Health, D-85764 Neuherberg, Germany.

Since its genetic identification, isoform 9 of the monocarboxylate transporter gene family (MCT9, SLC16A9) has been an 'orphan' transporter, ie with unknown substrate (review: Meredith \& Christian 2008, Xenobiotics). A hypothesis-free genome-wide association study using metabolomics has recently shown a very strong link between single nucleotide polymorphisms (SNPs) in MCT9 and lowered plasma carntine levels (Illig et al, 2010), raising the obvious question: is MCT9 a carnitine transporter?

The linearised human MCT9 clone (IMAGE 40146598) was used to synthesise capped mRNA in an in vitro run-off transcription reaction (Promega). Three days after injection into isolated Xenopus laevis oocytes, transport of $\left[{ }^{3} \mathrm{H}\right]$-carnitine was assayed using techniques similar to those previously reported (Meredith 2004, J Biol Chem).

Uptake experiments did not reveal and significant uptake, with if anything a trend towards a lower level of carnitine in MCT9-expressing oocytes than non-injected (NI) controls. Therefore MCT9-expressing oocytes were injected directly with $0.25 \times 10^{-3} \mathrm{MBq}$ of $\left[{ }^{3} \mathrm{H}\right]$-carnitine and incubated in $\mathrm{pH} 7.4$ medium to assess efflux. There was a significant increase in the efflux of carnitine from MCT9-expressing oocytes compared to the NI controls, with $37.3 \pm 4.9 \%$ less radioactivity remaining after 90 minutes (6-9 oocytes per data point, $\mathrm{p}<0.05$ student's t-test; $\mathrm{n}=2$ independent oocyte preparations). Unlike for other MCTs, efflux did not appear to be dependent on $\mathrm{pH}_{\text {out }}$.

These data are consistent with MCT9 being a transporter for carnitine as predicted by Illig et al (2010, Nat Genet), and when expressed in Xenopus oocytes acting as a uni-directional efflux system. Further transport characteristics and the tissue and cellular location(s) of MCT9 remain to be elucidated before we can understand how SNPs in MCT9 result in a lower plasma carnitine concentration. 


\section{Transport specifity of MCT1 in sheep rumen epithelium}

Reiko Rackwitz, Anke Schmidt-Mähne, Petra Philipp, Gotthold Gäbel

Institute of Veterinary Physiology, University of Leipzig, Germany

Although the localisation at the blood oriented side of rumen epithelium is well established, the functional characteristics of monocarboxylate-transporter 1 (MCT1) in this tissue are still under discussion. It may transport metabolites of short-chain fatty acids (SCFA) like beta-hydroxybutyrate as well as the SCFA. In our experiments, sheep rumen epithelium from the ventral sac was mounted in Ussing chambers filled with bicarbonate-free buffer solution $(\mathrm{pH} 7.4)$ on both sides and gassed with oxygen. All measurements were conducted under short-circuit conditions. The epithelia were loaded with SCFA by adding acetate and butyrate (10 $\mathrm{mM}$ both) to incubation solution on both sides. Either acetate or butyrate was ${ }^{14} \mathrm{C}$-labelled. After two hours of incubation the epithelia were washed three times and chambers were refilled with SCFA-free buffer solution. To detect side specific efflux of ${ }^{14} \mathrm{C}$-labelled SCFA and their metabolites we used the MCT1-blockers phloretine and p-hydroxymercuribenzoic acid (pHMB) at concentrations of 100 and $800 \mu \mathrm{M}$, respectively. Samples of mucosal and serosal buffer solution were taken 0, 30, 60 and 90 minutes after buffer replacement and measured in a scintillation counter. Appearance of ${ }^{14} \mathrm{C}$-labelled molecules was calculated by simple ratio equation. Results show that there was no significant difference in the mucosal appearance of ${ }^{14} \mathrm{C}$ between acetate and butyrate. Both phloretine and pHMB had no significant effect on the mucosal side. On the serosal side, appearance after incubation with labelled butyrate was approximately three times higher than that on mucosal side. Serosal ${ }^{14} \mathrm{C}$ appearance after incubation with labelled butyrate was significantly higher than that after incubation with labelled acetate. Phloretine and pHMB had no effect on the appearance of radioactivity on the serosal side in epithelia exposed to labelled butyrate. Both blockers raised serosal appearance of ${ }^{14} \mathrm{C}$ after incubation with labelled acetate considerably but not significantly $(\mathrm{p}=0.08$; One way ANOVA, $\mathrm{n}=5)$. Our results suggest that pathways for serosal efflux of SCFA differ from that of their metabolites. Assuming an enhanced lipophilic diffusion, the increased serosal ${ }^{14} \mathrm{C}$-appearance after phloretine and pHMB indicates that MCT1 may also be able to transport acetate. 


\section{Role of antidiabetic drugs on the regulation of PEPT1}

Patrick Hindlet, Claire Barraud, Laura Boschat, Robert Farinotti, André Bado, Marion Buyse.

Faculty of Pharmacy, University Paris-Sud 11, Chatenay-Malabry, France

Background and aims: PepT1 plays a major role in nitrogen supply to the body by mediating the intestinal absorption of $70 \%$ of total nitrogen in the di- and tripeptides form. We previously showed that PepT1 is regulated in a murin model of type 2 diabetes (T2D)/obesity. Moreover, we recently provided evidence in wild type mice that two major drugs used in T2D treatment, namely metformin and the PPAR $\gamma$ activator rosiglitazone (RSG), are potent regulators of PepT1. Thus, the next step consisted in investigating the regulation of the two aforementioned drugs in our model of T2D/obesity.

Methods: C56Bl/6J mice were kept on a high-fat (HF) or standard chow (SC) diet for 45 days in order to induce a phenotype of T2D/obesity and treated thereafter for 7 days with metformin $(250 \mathrm{mg} / \mathrm{kg} / \mathrm{d}$, po) or RSG $(8 \mathrm{mg} / \mathrm{kg} / \mathrm{j}$, po) or both. For in vitro studies, Caco2 cells were treated for 7 days with metformin (10 mM) or RSG $(10 \mu \mathrm{M})$ or both. PepT1 activity was studied following the Papp of ${ }^{3} \mathrm{H}-\mathrm{Gly}-\mathrm{Sar}$ by the jejunal ex vivo loop method or in vitro on Caco2 cells grown on Transwell ${ }^{\circledR}$. Protein and mRNA expression were studied by westernblotting and qPCR respectively for in vivo and in vitro studies.

Results: The HF diet induced a two-fold decrease in PepT1 activity, protein and mRNA expression. Moreover, a 7-days RSG treatment compensated this decrease by inducing a $50 \%$ increase in PepT1 activity and protein expression in both HF and SC mice but had no effect on mRNA levels. Metformin had no effect on these parameters, but when added to RSG, it totally abolished all its effects. In vitro experiments showed that RSG induced a 1.3-fold increase in Papp of Gly-Sar associated with protein expression. This regulation was mediated by the S6 ribosomal protein activation.

Conclusions: Taken together, these data indicate that PepT1 is down-regulated during T2D/obesity in mice and that RSG may reverse this phenotype. Moreover, we depicted RSG mechanism of action as being posttranscriptional. Finally, we could show that metformin had no effect per se in vivo but reverses RSG-mediated PepT1 activation. This particular point is currently under investigation in order to delineate the precise mechanism of action of metformin. 


\section{A six direct repeat motif of seven amino acids is involved in adaptation to cold of icefish}

\section{(Chionodraco hamatus) peptide transporter}

Antonia Rizzello ${ }^{\mathrm{a}}$, Alessandro Romano ${ }^{\mathrm{a}}$, Gabor Kottra ${ }^{\mathrm{b}}$, Raffaele Acierno ${ }^{\mathrm{a}}$, Carlo Storelli ${ }^{\mathrm{a}}$, Tiziano Verri ${ }^{\mathrm{a}}$, Hannelore Daniel ${ }^{\mathrm{b}}$, Michele Maffia ${ }^{\mathrm{a}}$.

${ }^{a}$ Laboratory of General Physiology, Department of Biological and Environmental Sciences and Technologies, University of Salento, via Provinciale Lecce-Monteroni, I-73100 Lecce, Italy, ${ }^{2}$ Molecular Nutrition Unit, Nutrition and Food Research Center, Technical University of Munich, Gregor-Mendel-Str. 2, D-85350 Freising-Weihenstephan, Germany

Icefish PEPT1, a novel piscine member of the SoLute Carrier 15 family, was identified in the intestine of the icefish Chionodraco hamatus, which normally lives in circum-Antarctic seawaters at $-1.9^{\circ} \mathrm{C}$. Despite its high similarity to other known vertebrate orthologues, icefish PEPT1 exhibited a remarkable cold adaptation, whose molecular basis was assessed by structural/functional studies. Icefish pept1 cDNA was obtained by RTPCR and 5'-/3'-RACE, functionally expressed in Xenopus laevis oocytes and subjected to two-electrode voltage clamp analysis. Icefish pept1 cDNA presented a 2274 bp open reading frame, encoding a 757 amino acids protein, the longest PEPT1 documented so far. As a distinctive feature icefish PEPT1 exhibited a unique six direct repeat motif of seven amino acids (VDMSRKS) in its carboxyterminal region, perfectly conserved among the repetitive units. Icefish PEPT1 kinetically resembled the other known vertebrate PEPT1's, displaying a $K_{0.5}$ for Gly-L-Gln of $0.12 \mathrm{mM}$ (at $-60 \mathrm{mV}$ and $\mathrm{pH}$ 6.5). However, its activation energy $\left(\mathrm{E}_{\mathrm{a}}\right)(78.66 \mathrm{~kJ} / \mathrm{mol})$ and $\mathrm{Q}_{10}$ (3.14) were significantly lower than those of rabbit (homeotherm) and zebrafish (tropical ectotherm) PEPT1 proteins (133 and $125 \mathrm{~kJ} / \mathrm{mol}$ for $\mathrm{E}_{\mathrm{a}}$ and 5.21 and 5.00 for $\mathrm{Q}_{10}$, respectively). Icefish PEPT1 lacking (by deletion) the hepta-repeats exhibited $E_{a}(102 \mathrm{~kJ} / \mathrm{mol})$ and $\mathrm{Q}_{10}(4.10)$ significantly higher than those of the wild-type protein, suggesting a role of this cytosolic region in the protein cold adaptation. The differences in the observed $\mathrm{E}_{\mathrm{a}}$ and $\mathrm{Q}_{10}$ of icefish when compared to other vertebrate PEPT1's may depend, at least in part, on the presence of these repeats near the carboxy terminus. 


\title{
Regional expression and function of $\mathrm{ABC}$ transporters in the GI-tract of rats
}

\author{
Caroline MacLean ${ }^{\mathrm{a}}$, Ulla Moenning ${ }^{\mathrm{b}}$, Andreas Reichel ${ }^{\mathrm{b}}$, Gert Fricker ${ }^{\mathrm{a}}$ \\ ${ }^{a}$ Pharmaceutical Technology and Biopharmacy, Institute of Pharmacy and Molecular Biotechnology, University of Heidelberg, Germany \\ ${ }^{b}$ Research Pharmacokinetics, Bayer Schering Pharma AG, Berlin, Germany
}

Intestinal $\mathrm{ABC}$ transporters may affect the bioavailability and effectiveness of orally administered drugs. However, available studies on regional expression of intestinal efflux transporters are mostly incomplete as they study only selected intestinal segments. For an evaluation of the consistency between mRNA and protein expression, relative expression levels of Pgp (ABCB1), Bcrp (ABCG2) and Mrp2 (ABCC2) were determined using qRT-PCR and Western blot analysis in rat intestinal segments from duodenum, jejunum, ileum and colon. In addition, the protein expression of Pgp, Bcrp and Mrp2 was studied by successive $3 \mathrm{~cm}$ segmentation of the entire intestine in order to evaluate the predictive power of expression analyses from selected intestinal segments. Pgp increased along the intestinal tract, whereas Bcrp showed an arcuate pattern of expression with an increase along the small intestine followed by a decrease in the large intestine. Mrp2 decreased continuously along the intestine. Regarding the concordance of mRNA and protein expression Pgp and Bcrp mRNA samples allow good estimations about the corresponding protein expression (for Pgp limited to the mdrla isoform) but for Mrp2 a pronounced deviation could be observed. All transporters showed considerable intra- and interindividual variability, particularly at the protein level, making it problematic to take transporter expressions of small sections exemplary for general and reliable assumptions on intestinal abundances. To assess the in vivo relevance of the detected patterns of expression, intestinal drug absorption was studied exemplarily for Pgp with the model compound fexofenadine, an antihistaminic drug. The drug was administered into ligated segments of upper and lower small intestine, corresponding to parts of the intestine with different levels of Pgp expression. It could be shown that the level of Pgp expression correlated well with the amount of Pgp substrate absorbed across the intestinal epithelium. Western blot experiments revealed a significant higher Pgp expression in the ileal segments than in the proximal segments. Accordingly, plasma concentrations of fexofenadine were significantly higher after administration into the proximal segment. Presence of PSC-833, a specific Pgp inhibitor, in the fexofenadine solution resulted in a significant increase of plasma concentrations in the ileal segments. This finding is consistent with an inhibition of distally expressed Pgp and subsequently a higher absorption of fexofenadine. 


\section{Regulatory Volume Decrease (RVD) process in isolated hepatocytes of the European sea bass, Dicentrarchus labrax \\ Hélène Ollivier $^{\mathrm{a}}$, Elisa Pelle ${ }^{\mathrm{b}}$, Federica Raffa ${ }^{\mathrm{b}}$, Caterina Faggio ${ }^{\mathrm{b}}$, Karine Pichavant-Rafini ${ }^{\mathrm{a}}$ \\ ${ }^{a}$ Laboratoire ORPHY, Université Européenne de Bretagne, Université de Brest, 6 avenue Le Gorgeu - CS 93837 - 29238 Brest Cedex 3 - \\ France 'Dipartimento di Scienze della Vita “M. Malpighi” sez. Fisiologia, Università di Messina, Viale Ferdinando D'Alcontres, 31-98166 Messina - Italia}

Cells of the European sea bass Dicentrarchus labrax are commonly exposed to large osmotic changes. In this study, we focus on the response of isolated hepatocytes to a decrease in extracellular osmolality from 320 $\mathrm{mosm} / \mathrm{kg}$ to $240 \mathrm{mosm} / \mathrm{kg}$. Our results show that sea bass hepatocytes swell by about $20 \%$ following hypoosmotic challenge and then have the capacity to perform a Regulatory Volume Decrease (RVD) process. At time 60 min after the shock, cells almost recover their initial volume. RVD is an integrative process that implies various signalling pathways ending at activation of regulatory effectors i.e. channels allowing release of organic and inorganic osmolytes. In sea bass hepatocytes, ATP appears as a central protagonist in the process since we observed that cells release this nucleotide in the extracellular medium when exposed to hypo-osmotic conditions. In this work, we highlighted that the release of ATP could imply membrane turnover since exocytotic activity of cells was increased following the hypo-osmotic shock, as attested by fluorescent dye FM1-43 experiments. As observed in other cell types, extracellular ATP could then act as an auto- or paracrine factor by binding to purinergic receptor triggering cascades of signalling events aimed at cell volume regulation. This work brings preliminary results about one of the most fundamental cellular homeostatic mechanism in a relevant model of marine teleost i.e. Dicentrarchus labrax. 


\section{INTESTINAL MICROBE-HOST INTERACTION}

\section{Mechanisms underlying upregulation of intestinal electrolyte absorption by probiotics}

Geetu Raheja, Alip Borthakur, Varsha Singh, Ravinder K Gill, Waddah A Alrefai, Jaleh Malakooti, Krishnamurthy Ramaswamy, Pradeep K Dudeja.

Department of Medicine, Section of Digestive Diseases \& Nutrition, University of Illinois at Chicago and Jesse Brown VA Medical Center, Chicago, IL, USA

Many Lactobacillus species have been successfully used in clinical trials to treat various forms of diarrhea in children. However, mechanisms underlying anti-diiarrheal effects of these probiotics are not well understood. Diarrhea involves either increased secretion of fluid and electrolytes, decreased absorption, or both. Electroneutral $\mathrm{NaCl}$ absorption in the human ileum and colon involves coupling of luminal $\mathrm{Na}^{+} / \mathrm{H}^{+}$exchange (NHE) and $\mathrm{Cl}^{-} / \mathrm{OH}^{-}\left(\mathrm{HCO}_{3}{ }^{-}\right)$exchange activities. We hypothesized that one of the mechanism by which probiotics act as anti-diarrheal agents involves stimulation of intestinal $\mathrm{NaCl}$ absorption. In an attempt to test our hypothesis, the effects of these bacteria on electroneutral $\mathrm{NaCl}$ absorption in the intestine was examined utilizing Caco2 monolayers as an in vitro model. Some of these in vitro results were also validated in mouse model. Our studies demonstrated that short-term (3h) treatment of Caco-2 monolayers with L. acidophilus or its culture supernatant stimulated $\mathrm{Cl}^{-} / \mathrm{OH}^{-}$exchange activity via enhanced apical membrane DRA (SLC26A3, the predomiant luminal $\mathrm{Cl}^{-} / \mathrm{OH}^{-}$exchanger) levels involving a PI-3 kinase dependent mechanism. The effect of longterm $(8-24 \mathrm{~h})$ exposure of these lactobacillus species or their culture supernatants on the mRNA and protein levels of these transporters as well as on their promoter activity was also examined. Our data demonstrated that lactobacillus acidophilus significantly enhanced the expression of DRA as well as NHE3 (the predominant $\mathrm{Na}^{+}$ absorbing isoform) in Caco-2 cells via transcriptional mechanisms and also stimulated DRA and NHE3 expression in in vivo mouse models as well.

Conclusion: Our results indicate that short-term stimulation of $\mathrm{Cl}^{-} / \mathrm{OH}^{-}$exchanger activity via increased apical levels of DRA as well as increased expression of DRA and NHE3 in response to long-term exposure to lactobacillus species could contribute to anti-diarrheal effects of these probiotics.

Supported by NIDDK and Dept. of Veterans Affairs. 


\section{A "Paleolithic" diet affects the bacteria flora in the small bowel of conventional pigs}

Danuta Kruszewska ${ }^{\mathrm{a}, \mathrm{b}}$, Björn Weström ${ }^{\mathrm{a}}$, Staffan Lindeberg, ${ }^{, \mathrm{c}}$, Stefan G. Pierzynowski ${ }^{\mathrm{a}, \mathrm{b}}$

${ }^{a}$ Dept Biology, Lund University, Sölvegatan 35, S-223 62 Lund, Sweden; ${ }^{b}$ Dept Medical Biology, IMW, Jaczewskiego 2, 20-950 Lublin, Poland; ${ }^{c}$ Dept Internal Medicine, Lund University, Sweden.

Recently, the principles of evolutionary biology have been incorporated into nutritional advice and preventive medicine. Studies in non-westernized humans, suggest that paleolithic diets largely prevent typical age-related processes such as insulin resistance, atherosclerosis, abdominal overweight and increasing blood pressure. The aim of the study was to study how diets similar to those of our human ancestors influence the bacteria count in the small intestine of pigs. The study was carried out on contents obtained from the proximal and distal small intestine from1 year old pigs fed a 'stone age' diet $(n=8)$ or a standard diet $(n=9)$. Samples of the mucosal was rinsed with sterile saline solution, dried with sterile cotton tampon and then stored at $-40{ }^{\circ} \mathrm{C}$. At analysis, the intestinal samples were weighed, cut into small pieces and homogenized. Colony forming unit (CFU) assay was used to determine the presence of viable microbial cells in one gram of pig intestine. The colonies were counted after $24 \mathrm{~h}$ incubation in a proper solid media at $36^{\circ} \mathrm{C}$. The limit of colony detection was $<$ $4 \times 10^{3} \mathrm{cfu} / \mathrm{mL}$. The amount of viable bacteria present in the proximal intestine of pigs fed with the 'stone age' diet was $2.92 \times 10^{4} / \mathrm{g}$ (homogenized material) compared to $2.38 \times 10^{4} / \mathrm{g}$ from pigs fed with a standard diet. In the distal small bowel of the pigs fed with the standard diet $2.17 \times 10^{4} \mathrm{cfu} / \mathrm{g}$ was found, while in that of the pigs fed with the 'stone age' diet the amount of bacteria was significantly higher, i.e., $7.35 \times 10^{4} \mathrm{cfu} / \mathrm{g}(\mathrm{p}<0.043)$. The amount of anaerobic bacteria detected in the proximal small intestine from the same tissues was more then 1.5 times higher then for the aerobes. CFUs in the proximal small intestine from animals fed with 'stone age' and standard diet was $4.9 \times 10^{4} / \mathrm{g}$ and $4.11 \times 10^{4} / \mathrm{g}$, respectively. In the distal part of the small intestine it was possible to isolate $1.21 \times 10^{5} / \mathrm{g}$ anaerobic bacteria while in the control group this figure was only $3.84 \times 10^{4} / \mathrm{g}(\mathrm{p}<0.043)$. A 'stone age' diet appear to influence, quantitatively and qualitatively the small intestinal microflora. 


\section{Kinetics of Biofilm Formation by Lactobacillus plantarum}

Elisa Lazzeri, Gianni Pozzi

Lab. of Molecular Microbiology and Biotechnology (LAMMB), Dept. of Molecular Biology, Univ. of Siena, Italy.

Lactobacillus plantarum is major colonizer of the mucosa of the human gastrointestinal tract and some strains are used as probiotics for human consumption. L. plantarum is also found in a diverse variety of ecological niches including vegetable and plant fermentations. Biofilm formation by L. plantarum strain NCIMB8826 was studied in a static model where the liquid phase was a semi-defined growth medium and the solid phase was the well of flat-bottomed polystyrene tissue culture plates. Experiments were performed using an inoculum of $4 \times 10^{7} \mathrm{cfu} / \mathrm{ml}$ and a surface-to-volume ratio of 1.2. The kinetics of biofilm formation was studied taking samples for 24 hours at 1-hour intervals. Quantitative parameters assessed included (i) growth in liquid phase, (ii) bacterial adhesion to solid phase, (iii) presence of an extracellular carbohydrate (EC) matrix, (iv) homologous coaggregation, (v) adhesion efficiency, and (vi) coaggregation efficiency. L. plantarum NCIMB8826 was found to efficiently form a biofilm in which bacterial cells are embedded in an EC matrix. Bacteria firmly adhering to the plastic surface form the first layer of the biofilm, to which coaggregating bacteria are loosely attached to form a second layer that can become very thick in mature biofilms. In this model, biofilm formation appeared to occur in 3 stages which correlate with the growth phases of bacteria in the liquid medium: (i) colonization (from inoculum to early exponential phase) (ii) biofilm development (exponential phase), and (iii) biofilm maturation (stationary phase). In the first hours after the inoculum, the "colonization stage", there is no growth in the liquid phase and bacteria colonize very efficiently the plastic surface. Bacterial adhesion at this stage is, on the average, $21 \%$ of the maximum value, while EC matrix is constantly present at levels which represent $25 \%$ of the maximum, and homologous coaggregation shows the lowest absolute values (below $1 \%$ of the maximum). It should be noted however that in this stage bacterial adhesion and homologous coaggregation are at the peack of efficiency, namely the majority of the bacteria present in the well are actually forming a biofilm on the plastic surface. In the "biofilm development" stage, while bacterial cells grow exponentially in the liquid phase, biofilm develops at the bottom of the well. Bacterial adhesion, EC matrix and homologous coaggregation all reach their peak values at the end of this stage, when cells growing in the liquid medium enter in the stationary phase. Maximum values registered during the time course were as follows: (i) bacterial adhesion, $1.7 \mathrm{OD}$ units $/ \mathrm{cm}^{2}$ (crystal violet staining), corresponding to $0.8 \times 10^{7} \mathrm{cfu} / \mathrm{cm}^{2}$; (ii) EC matrix, 26.6 $\mu \mathrm{g} / \mathrm{cm}^{2}$ (anthrone method); (iii) homologous coaggregation, 1.1 OD units per $\mathrm{cm}^{2}$ (turbidimetric measurement), corresponding $3.3 \times 10^{9} \mathrm{cfu} / \mathrm{cm}^{2}$. The "maturation stage" is characterized by a wide fluctuation of all parameters. This biofilm model by allowing kinetic determination of several quantitative parameters can be used to study regulation of gene expression in biofilm formation, as well as the environmental signals involved in this regulation. 


\section{Analysis of the genome sequence of Bifidobacterium bifidum PRL2010}

Francesca Turroni ${ }^{a}$, Elena Foroni ${ }^{1}$, Francesca Bottacini ${ }^{a}$, Jae-Han Kim ${ }^{b}$, Borja Sànchez Garcia ${ }^{c}$, Alberto Ferrarini $^{4}$, Alessandro Bidossi ${ }^{\mathrm{e}}$; Marco Oggioni ${ }^{\mathrm{e}}$, Massimo Delledonne ${ }^{\mathrm{d}}$, David A Mills $\mathrm{s}^{\mathrm{b}}$, Abelardo Margolles ${ }^{\mathrm{c}}$, Douwe van Sinderen ${ }^{\mathrm{f}}$, Marco Ventura ${ }^{\mathrm{a}}$

Laboratory of Probiogenomics, Department of Genetics, Biology of Microorganisms, Anthropology and Evolution University of Parma, Italy ${ }^{a}$; Department of Viticulture and Enology, University of California, Davis, CA, USA ${ }^{b}$; Department of Microbiology and Biochemistry of Dairy Products. Istituto de Productos Làcteos de Asturias (CSIC), Villaviciosa, Asturias, Spain ; Dipartimento Sientifico Tecnologico, Università degli Studi di Verona, Verona, Italy ${ }^{d}$; Department of Molecular biology, University of Siena. Italy; Alimentary Pharmabiotic Centre and Department of Microbiology, Bioscience Institute, National University of Ireland, Western Road, Cork, Ireland'.

The human intestine is highly dense colonised by a microbiota whose metabolism is largely affected by the presence of members of the genus Bifidobacterium. Nevertheless, the molecular basis of adaptation of these bacteria to the human gut is still largely unknown. Accordingly, the complete genome sequences of Bifidobacterium bifidum PRL2010 reflect a competitive nutrient-utilization strategy targeting host-glycans. The genome of B. bifidum PRL2010, an infant stool isolates, was decoded to uncover a single circular 2,214,650 base pair chromosome with 1844 predicted open reading frames. Annotation of the genome sequence revealed multiple ways in which B. bifidum PRL2010 has adapted to the human intestinal environment through specialized nutrient acquisition. Several chromosomal loci reflect potential adaptation of this strain to the breakdown of host produced-mucin, including catabolic genes, and permeases predicted to be active on mucinoligosaccharides. Whole proteome profiling was used to define the genetic mechanisms underlying host-glycan foraging. Finally, conservation of gene clusters in multiple isolates of B. bifidum was assayed by comparative genomic hybridizations. The B. bifidum mediated glycans catabolism is an important component in gut colonization and may influence intestinal microbial ecology. 


\title{
Lactobacillus plantarum enhances human intestinal barrier function via a TLR2 and
} PKC $\delta$ - mediated mechanism

\author{
Juergen Karczewski ${ }^{\mathrm{ab}}$, Peter van Baarlen ${ }^{\mathrm{ab}}$, Jan Dekker ${ }^{\mathrm{b}}$ and Jerry Wells ${ }^{\mathrm{ab}}$ \\ ${ }^{a}$ Host Microbe Interactomics, University of Wageningen, The Netherlands. \\ ${ }^{b}$ TI Food \& Nutrition, Nieuwe Kanaal 9a. 6709 PA Wageningen, The Netherlands
}

L. plantarum (LP), a commensal bacterium of humans, is able to modify the intestinal barrier in of human volunteers and intestinal cell-lines via a Toll like receptor (TLR) 2 pathway. To study the mechanism by which TLR signaling can modify tight junction proteins a genomic study was performed. Caco-2 BBE cells were treated for 2 and 6 hrs with LP, and TLR2 ligands PAM $_{3}$ CSK and lipoteichoic acid isolated from LP.

538 genes were differentially regulated after 6 hrs exposure to LP ( $\mathrm{p} \leq 0.01)$. No unregulated expression of tight junction proteins or tight junction associated proteins was observed but network analysis indicated that epithelial cells remodel after TLR2 stimulation. Affected networks include: Cellular Development, Lipid Metabolism, Molecular Transport, Cellular Assembly and Organization, Post-Translational Modification and Lipid Metabolism. Using confocal laser scanning microscopy, phosphorylation of ERK1/2 and p38 was observed in LP, LTA and PAM $_{3}$ CSK -treated Caco-2 cells. Furthermore, we observed TLR2 induced translocation of cytosolic $\mathrm{PKC} \delta$ towards the apical part of the cell and to the tight junctions. Analysis of human biopsies of the duodenum also showed a very strong apical and junctional staining of PKC $\delta$ in villus cells. Surprisingly, no PKC $\delta$ was observed in crypt cells of the duodenal biopsy. This suggests that $\mathrm{PKC} \delta$ is associated with differentiation of crypt cells into villus epithelial cells. TLR2 signaling can enhance the activation of PKC $\delta$ which may play a role in the modification of tight junctions. We are now investigating the specific targets of PKC $\delta$ in TLR2 triggered intestinal epithelial cells 


\title{
Response of two intestinal epithelial cell lines to incubation with Enterococcus faecium and pathogenic Escherichia coli
}

\author{
Julia Strahlendorf ${ }^{\mathrm{a}}$, Peter Schierack ${ }^{\mathrm{b}}$, Holger Martens ${ }^{\mathrm{a}}$, Ulrike Lodemann ${ }^{\mathrm{a}}$ \\ ${ }^{\mathrm{a}}$ Institut für Veterinär-Physiologie, ${ }^{\mathrm{b}}$ Institut für Mikrobiologie und Tierseuchen, Freie Universität Berlin
}

Background \& Aims: Positive effects of probiotics on the barrier function of intestinal epithelia have been reported in various animal models or human cell culture studies. In the framework of DFG research group 438 ("Integrative analysis of modes of action of probiotics in pigs"), we were interested in possible protective mechanisms of probiotics licensed for pigs and in the use of adequate models for this type of study. We compared a human and a porcine cell culture model with regard to their response to incubation with pathogenic E. coli and probiotic E. faecium strains. We assessed the barrier function of the epithelia. We also tested the hypotheses of whether protective or anti- or proinflammatory mechanisms of the cell are activated.

Methods: The porcine intestinal epithelial cell line IPEC-J2 and the colon carcinoma cell line Caco-2 were used in parallel. Cells were incubated with various bacterial strains and their combinations (E. faecium NCIMB 10415 and pathogenic E. coli). The transepithelial electrical resistance (TEER) was measured with a voltohmmeter, and mannitol flux rates were concomitantly recorded. Quantitative PCR for the expression of heat shock proteins (Hsps) and cytokines was performed in an iCycler Thermal Cycler (Biorad) with SYBR green detection.

Results: Time dependent changes in TEER in response to bacterial incubation were paralleled by changes in mannitol flux rates. These alterations differed depending on bacterial strains and cell lines. Hsp70 mRNA expression was induced by pathogenic E. coli in Caco-2 cells, whereas no consistent effect could be measured in IPEC-J2 cells within the set time frame (10 h). IL-8 mRNA expression was enhanced after E. coli treatment in both cell lines. Preincubation with E. faecium ameliorated the effects of pathogenic bacteria. Conclusions: $E$. faecium might have a protecting effect with regard to the damage caused by E. coli to epithelial function, but these effects differ depending on the cell line.

This study was supported by DFG FOR 438. 


\section{Ultrastructural organization of biofilms of opportunistic microorganisms representatives of gut human microbiota}

Rybalchenko Oxana $^{\mathrm{ab}}$, Bondarenko Victor ${ }^{\mathrm{b}}$, Rozlomiy Valentin ${ }^{\mathrm{a}}$, Orlova Olga ${ }^{\mathrm{ab}}$

${ }^{\mathrm{a}}$ State University of St. Petersburg and ${ }^{\mathrm{b}}$ Institute of Highly Pure Biopreparations, St. Petersburg, Russia

Opportunistic bacteria taking part in the colonization of the gastrointestinal tract can form biofilms microbial communities, which, like the bacterial colony, are capable to doing the cover in the intestine surface by mucous membranes. Formation of biofilms associated with communicative manifestation of «a sense of quorum» (Quorum Sensing) in bacteria in communities characterized by high population density and high physiological activity of its constituent individuals. The problem of suppression of bacterial films is still an urgent task, since in some cases, causal treatment of various infectious processes is inefficient because of high drug resistance of "biofilm forms" of the parasite and their morphological and functional features which haven't been studied enough. The aim of the study was - electron microscopic study of ultrastructural organization of homogeneous and mixed microbial communities (in vitro) of opportunistic microorganisms representatives of the human normal microbiota in the formation of biofilms. Process of biofilm formation by opportunistic microorganisms belonging to different genus was analyzed by electron microscopy (on scanning and transmission microscopy). It is shown that biofilms of homogeneous and mixed microbial communities of various genus of Enterobacteriaceae and Staphylococcus, Enterococcus, Pseudomonas and Candida are protected the microbial cells from the air by original complex surface structures combining all the cells into a single system, providing contact with the external environment as well as individual cells and the entire bacterial community. Increased resistance of bacteria to the action of various damaging factors is associated with the screening of cells in the biofilm polysaccharide layers of intercellular matrix, filling the thickness of the microbial community. Morphological and functional properties of the biofilms provide the resistance of microbial community to the environment damage factors, increase resistance to antibiotics and immune protection system. 


\section{Molecular characterization of mobile elements carrying antibiotic resistance genes in foodborne Lactic Acid Bacteria that colonize the human gut}

Chiara Devirgiliis, Simona Barile, Giuditta Perozzi.

INRAN - National Research Institute on Food and Nutrition, Via Ardeatina 546, 00178 Roma, Italy

The use of antibiotics as growth promoters in livestock led to selection and spread of antibiotic resistance (AR) within environmental bacteria. Food borne antibiotic-resistant Lactic Acid Bacteria (LAB) have received growing attention in the past few years, as they represent a reservoir of antibiotic resistance genes potentially transmissible to bacterial species that colonize the human gut, including opportunistic pathogens. We have recently identified a tetracycline and erythromycin resistant strain of Lactococcus lactis, as well as a tetracycline resistant strain of Streptococcus bovis, isolated from raw milk and natural whey starter cultures employed in the manufacture of a traditional Italian dairy product. Molecular analysis of the antibiotic resistance determinants in Lc. lactis identified them as plasmid-borne $\operatorname{tet}(\mathrm{S})$ and $\operatorname{erm}(\mathrm{B})$ genes, linked through an intervening $7 \mathrm{~Kb}$ region. Complete nucleotide sequence of the $18 \mathrm{Kbp}$ plasmid revealed the presence of 13 putative open reading frames (ORF) and an ori region resembling those of theta-replicating plasmids. In S. bovis we identified a pK214-like element, carrying a chimeric $\operatorname{tet}(\mathrm{S})-\operatorname{tet}(\mathrm{M})$ gene, in which only the initial 5 aminoacids of $\operatorname{tet}(\mathrm{S})$ are retained, as in-frame fusion with the entire coding region of $\operatorname{tet}(\mathrm{M})$. This element was found as a $4.3 \mathrm{~Kb}$ circular form lacking a replication origin, as well as integrated within the chromosome. Detailed molecular characterization of the element and of the surrounding genomic context revealed that integration occurs in a chromosomal region containing blocks of sequence homology with the genomes of Streptococcus infantarius and Lactococcus lactis KF147. Moreover, the chimeric $\operatorname{tet}(\mathrm{S})-\operatorname{tet}(\mathrm{M})$ gene is flanked by two copies of the insertion sequence IS1216, associated to transposase genes, suggesting that the element could be horizontally transferred. To ascertain the potential risk for human health we are presently performing in vitro and in vivo conjugal transfer experiments with different recipient species, known to efficiently colonize the human gut, with special attention to opportunistic pathogens such as Enterococcus faecalis.

Work supported by grant NUME (DM 3688/7303/08) from the Italian Ministry of Agriculture, Food \& Forestry (MiPAAF). 


\section{DISEASES OF THE GI TRACT}

\section{Extremely low glutathione levels in colonic mucosa of HLA-B27 transgenic rats developing colitis: no effect of supplemental antioxidants}

Marloes Schepens, Carolien Vink, Arjan Schonewille, Roelof van der Meer, Ingeborg Bovee-Oudenhoven

TI Food and Nutrition, Wageningen and NIZO food research, Ede, The Netherlands

Introduction: The HLA-B27 transgenic rat is widely used as an animal model in IBD research. IBD is characterized by mucosal influx and activation of leukocytes, supposedly leading to oxidative stress and subsequent mucosal damage.

Aims: We were interested in the oxidative stress status of HLA-B27 rats, and whether supplemental antioxidants (AOX) would be protective.

Methods: HLA-B27 rats and their wild-type (WT) counterparts were fed a Western control diet, or the same diet supplemented with an AOX mixture of glutathione (GSH), vitamin $\mathrm{C}$ and vitamin E. Oxidative damage was determined by thiobarbituric acid reactive substances (TBARS) and protein carbonyls in colonic mucosa. The colonic AOX status was analyzed by its GSH content, and the ferric reducing ability assay (FRAP) reflecting the non-thiol AOX capacity. Moreover, colonic inflammation, intestinal permeability and diarrhea were quantified.

Results: As expected, intestinal permeability, colonic inflammation, and diarrhea were increased in HLAB27 rats. Remarkably, oxidative stress-related damage and the non-thiol AOX capacity were not changed in transgenic rats compared to WT rats. However, colonic GSH levels were more than 50-fold lower in HLA-B27 rats than in WT rats. Subsequent analyses showed no defect in mRNA expression of GSH synthesis genes but revealed elevated cysteine and cysteamine levels in HLA-B27 rats compared to WT rats. The AOX supplement neither improved permeability, diarrhea and inflammatory parameters, nor affected oxidative stress markers.

Discussion: HLA-B27 transgenic rats do not show oxidative stress in colonic mucosa despite colitis development. Therefore, AOX supplementation might have been ineffective. Surprisingly, GSH levels were extremely low in colonic mucosa. This might be due to the high concentrations of cysteamine, which is an inhibitor of GSH synthesis. Further investigations are ongoing to determine whether the low GSH levels are a cause or a consequence of the colitis development. 


\section{Liprotamase, a microbially derived enzyme preparation, restores growth in pigs with Exocrine Pancreas Insufficiency (EPI) \\ Jose Luis Valverde Piedra, ${ }^{\mathrm{a}, \mathrm{b}}$, Sylwia Szymanczyk ${ }^{\mathrm{a}, \mathrm{b}}$, Danica Grujic ${ }^{\mathrm{c}}$, Katarzyna Szwiec ${ }^{\mathrm{a}, \mathrm{b}}$, Tomasz Bala ${ }^{\mathrm{a}, \mathrm{b}}$, Björn Weström $^{\mathrm{a}}$, Stefan G. Pierzynowski ${ }^{\mathrm{a}, \mathrm{d}}$ \\ ${ }^{a}$ Dept Biology, Lund University, Sölvegatan 35, S-223 62 LUND, Sweden; ${ }^{b}$ Dept Biochem \& Animal Physiol. Life Science Univ, ul. Akademicka 12. Lublin, Poland; 'Alnara Pharmaceuticals, Cambridge, MA, USA; ${ }^{d}$ Dept Medical Biology, IMW, Jaczewskiego 2, Lublin, Poland.}

The standard therapy for EPI in humans is porcine-derived pancreatic enzyme therapy. EPI can be induced in pigs by pancreatic duct ligation causing a total lack of pancreatic enzymes and diminished levels of bicarbonate resulting in poor lipid and protein absorption, steatorrhea and arrested growth. This study tested the efficacy of a novel microbial enzyme product, Liprotamase rapid disintegrating tablets, intended for the treatment of children and adults with pancreatic insufficiency, in young EPI pigs. Two doses of Liprotamase, high (256,000 U Lipase, 24,000 U Amylase, 194,400 U Protease) and low (129,600 U Lipase, 12,000 U Amylase, 102,000 U Protease) or placebo were given bi- daily with a high fat diet to seven EPI pigs (10 wks, $14.0 \pm 1.8 \mathrm{~kg}$ ). The study included 1 control and 2 treatment periods (each $1 \mathrm{wk}$ ) with a washout in between, in a cross over design. Raw fat and nitrogen were measured in feed and stool to calculate the coefficient of fat (\%CFA) or protein absorption (\%CNA). Postprandial changes in blood triglycerides (TG) and body weight gain were measured. One week of treatment with Liprotamase normalized stool appearance, decreased stool weight by $37 \%$, with treatment CFA of 84 and CNA of $60 \%$. Liprotamase improved lipid absorption by doubling postprandial serum TG to $0.7 \mathrm{mmol} / \mathrm{L} 3 \mathrm{~h}$ after a meal. As a result, body weight gain increased $6.1 \%$ and $8.1 \%$ respectively with the two tested doses. Overall, Liprotamase treatment allowed proper digestion and absorption of nutrients leading to near normal growth of EPI pigs. Thus, Liprotamase represents an effective and attractive alternative (fewer tablets and zoonose risk free) to traditional porcine enzyme therapy for treatment of EPI. 
Isolation and characterization of circulating tissue transglutaminase-specific $\mathbf{T}$ cells in coeliac disease

Rachele Ciccocioppo ${ }^{\mathrm{a}}$, Alberto Finamore ${ }^{\mathrm{b}}$, Elena Mengheri ${ }^{\mathrm{b}}$, Danilo Millimaggi ${ }^{\mathrm{c}}$, Birgit Esslinger ${ }^{\mathrm{d}}$, Walburga Dieterich $^{\mathrm{d}}$, Franc Papola ${ }^{\mathrm{c}}$, Simonetta Colangeli ${ }^{\mathrm{c}}$, Vincenzo Tombolino ${ }^{\mathrm{c}}$, Dieterich Schuppan ${ }^{\mathrm{e}}$, Gino Roberto Corazza $^{\mathrm{a}}$

${ }^{a}$ Center for the Study and Cure of Coeliac Disease, IRCCS Policlinico San Matteo Foundation, University of Pavia; ${ }^{b} I N R A N$, Rome; ${ }^{c}$ Dept. Experimental Medicine, University of L'Aquila; Italy. ${ }^{c}$ Dept. Medicine, University of Erlangen-Neuernberg, Germany. ${ }^{d}$ Beth Israel Deaconess Medical Center, Harvard Medical School, Boston, MA; USA

Tissue transglutaminase (TG2) was identified as the humoral autoantigen in coeliac disease, but whether it can also serve as $\mathrm{T}$ cell autoantigen is still unknown. The aims of our work were, firstly to explore the presence of TG2-specific T cells in peripheral blood of ten adult patients (four active, i.e. four treated for an adequate period of gluten free diet; and two potential coeliacs), and four healthy controls (two carrying the HLA-DQ2 haplotype of susceptibility to the disease), and secondly to carry out a detailed in vitro characterization of the isolated antigen-specific $\mathrm{T}$ cells. $\mathrm{T}$ cell lines were first established with human recombinant TG2 followed by generation of $\mathrm{T}$ cell clones through limiting dilution method and further rounds of TG2 stimulation. Antigen specificity and HLA-DQ2 restriction were both assessed by evaluating the proliferative response to TG2 in the absence and presence of human sera blocking HLA-DQ2 molecules. Immune phenotyping of T cell clones was performed by flow cytometry, and the expression of IL-1b, IL-4, IL-6, IL-10, IL-12, TGF-b, IFN-g and TNF-a was determined by ELISA assay on the supernatants of obtained clones. A total of $91 \mathrm{~T}$ cell clones were isolated from the three HLA-DQ2-positive, active patients, but none from the other patients and controls. The immune phenotyping showed that the majority of them $(85.7 \%)$ were $\mathrm{CD} 3 / \mathrm{CD}^{+}$and only a small percentage $(14.3 \%)$ were $\mathrm{CD} 3 / \mathrm{CD}^{+}$, all carried the TCR ab, and had a memory phenotype. The cytokine profile showed high levels of IFN-g and IL-6 that, together with the absence of IL-4, placed these T cell clones in the Thelper type 1-like category. Further in vitro analysis was carried out on 32/91 $\mathrm{CD}^{+}$clones and showed a specific and dosedependent proliferative response towards TG2 and an HLA-DQ2 restriction. Finally, when incubating duodenal mucosal specimens of treated patients with the supernatant of TG2-specific T cell clones, characteristic disease lesions were found, indicating a role for TG2-specific cellular immune response in the pathogenesis of coeliac disease. 


\section{Effect of experimental colitis on enterocyte transport related genes assessed by microarray analysis}

Isabel Romero-Calvo, Cristina Mascaraque, Antonio Zarzuelo, María Dolores Suárez, Olga Martínez-Augustin, Fermín Sánchez de Medina

Departments of Pharmacology and Biochemistry and Molecular Biology II, CIBER-EHD, School of Pharmacy, University of Granada, Spain.

Background \& aims: The inflamed intestine is characterized by a state of inhibited ionic secretion and absorption. We aimed at relating this behaviour with changes in gene expression.

Methods: We present a genomic microarray analysis of the transcriptome of colonic epithelial cells isolated by calcium chelation and percoll purification. The transcriptome was characterized with Affymetrix RAE 2302.0 microarrays (1 per group, with pooled samples) with RT-qPCR confirmation in some cases.

Results: inflammation changed the expression of 5815 sequences, of which approximately half were upregulated and half downregulated. Ingenuity analysis showed that the main functions affected were protein synthesis and trafficking, molecular transport and RNA postranscriptional modification. Focusing on ionic transport, the mRNA expression of the absorptive transporters NHE3 (Slc9a3) and Scnn1b (ENaC beta subunit) were increased by 3.03 and 2.83 respectively, while that of DRA (Slc26a3), NHE2 (Slc9a2) and Scnn1g (gamma subunit) were unchanged. Cftr was upregulated by a similar amount (2.46). The expression of $\mathrm{Na} / \mathrm{K}$ ATPase subunits b1 and a1 was similarly increased. Thus there is no apparent correlation with actual ion transport, suggesting modulation at protein expression or regulation instead. The analysis of the transcriptome shows some changes in the cAMP/PKA pathway. Thus G!s (Gnas) and G!i (Gnai3) were increased. However, the addition of pertussis toxin to inflamed rat colon mounted in Ussing chambers lowered basal and carbachol evoked response, but to a similar degree than it does in uninflamed tissue. Also, Western blot of enterocytes showed increased expression of the EP2 prostaglandin receptor (which couples to G!s) under inflammation, indicating that this is not a limiting factor in cAMP generation by prostaglandins. On the other hand, the mRNA levels of adenylate cyclase 9, the isoform showing the maximal expression in enterocytes, was decreased 3.4 fold. Augmented mRNA levels of Fxyd4 and 5, which are important regulators of Na/K ATPase, were also detected, suggesting a possible involvement in transport alterations. Several genes involved in epithelial tight junction structure were downregulated, including claudin 4, junctional adhesion molecule 1 (F11r) and occludin.

Conclusions: the alterations in ion transport do not seem to be explained by changes in transporter mRNA levels, but they may be related to changes in regulatory genes. 


\title{
The tight junction protein tricellulin in Crohn's disease and ulcerative colitis
}

\author{
Susanne M Krug ${ }^{\mathrm{a}}$, Christian Bojarski ${ }^{\mathrm{b}}$, Anja Fromm ${ }^{\mathrm{a}, \mathrm{c}}$, Jörg D Schulzke ${ }^{\mathrm{b}, \mathrm{c}}$, Michael Fromm ${ }^{\mathrm{a}}$ \\ ${ }^{a}$ Institute of Clinical Physiology; ${ }^{b}$ Dept. of Gastroenterology; ${ }^{c}$ Dept. of General Medicine, Campus Benjamin Franklin, Charité Berlin, \\ Germany
}

Within tricellular meeting points of three cells, the recently discovered tight junction (TJ) protein tricellulin-a (TRIC) is predominantly located. There it forms a barrier to macromolecules without affecting ion permeability. At low expression levels the tricellular TJ (tTJ) forms a pathway for macromolecules, presumably built by the central tube of the tTJ. Tricellular tight junctions thus form "rare large pores" independent of "frequent small pores" for ions which reside in bicellular TJs. In this study the pathologic relevance of TRIC expression in Crohn's disease (CD) and ulcerative colitis (UC) was analyzed.

Methods. Dilution potentials and permeabilities for fluorescein and FITC-dextran 4K were measured in sigmoid colon biopsies from controls, active CD patients, and UC patients using the Ussing technique. Epithelial and subepithelial resistances were determined by impedance spectroscopy. Expressions of TRIC and other TJ proteins were analyzed by Western blot.

Results. In sigmoid colon biopsies from UC patients, but not in CD biopsies, expression of TRIC was reduced. This was in parallel to already known changes in expression of e.g. claudin-4. UC specimens exhibited decreased epithelial resistance, increased subepithelial resistance, and unchanged transepithelial resistance. Permeabilities for $\mathrm{Na}^{+}$and $\mathrm{Cl}^{-}$were unchanged, but in contrast, permeabilities for fluorescein and FITC-dextran $4 \mathrm{~K}$ were increased.

Conclusion. While TRIC expression is not influenced in Crohn's disease, it is downregulated in ulcerative colitis. As TRIC limits the macromolecular passage in tTJs, its downregulation may contribute to the increased macromolecular permeability in ulcerative colitis. (Supported by DFG Research Unit FOR 721) 


\section{Coffee and reduction of diabetes type 2 risk: a possible mechanism of action}

Guido Leoni, Fausta Natella

National Research Institute on Food and Nutrition (INRAN), Rome Italy

Type 2 diabetes (T2DM) belongs to the group of dismetabolic diseases characterized by iperglicemy, dislipidemy and altered protein metabolism. Essentially T2DM is characterized by a reduced use of hematic glucose after an absolute or relative deficiency of insulin. Several epidemiologic studies report that a habitual consumption of coffee is associated to a reduced risk of T2DM and this association is still valid also considering decaffeinated coffee consumption. Recently it has been suggested that the protective effect of coffee against T2DM is related to the capacity of coffee phenolic compounds to inhibit intestinal glucose transport. We hypothesise that coffee phenolic compounds could also be able to directly inhibit salivary and intestinal enzymes that hydrolize complex carbohydrates, thus slowing glucose digestion and lowering plasma glucose level. Our hypothesis has been verified testing coffee, caffeine and the three coffee phenolic compounds (caffeic acid, ferulic acid and chlorogenic acid) on salivary and intestinal a-glucosidase and a-amylase activity and using two different approach: 1) in vitro enzymatic inhibition assay and 2) in silico docking analyses. The results of the in vitro assay suggest that coffee and coffee phenolic compounds are able to inhibit the maltase activity of rat intestine but not human salivary a-amylase activity. The three coffee phenolic compounds showed an inhibitory activity (IC50) ranging from 50 to $200 \mu \mathrm{M}$ and following the order: caffeic acid $>$ chlorogenic acid $>$ ferulic acid. The docking analysis demonstrates that the action of the three phenolic compounds could be linked to a direct antagonism in the active site of the hydrolytic enzymes, blocking the residues responsible for the cleavage of the anomeric carbonium in oligosaccharides (natural substrate of the enzymes). This mechanism is similar, but less effective, of the binding mode of the acarbose (a molecule commonly used in T2DM therapy). 


\title{
Optimization of a small intestinal segment perfusion model for heat-stable enterotoxin $A$
} induced secretion in pigs

\author{
Michaela Loos ${ }^{\mathrm{a}}$, Ann Hellemans ${ }^{\mathrm{b}}$, Eric Cox ${ }^{\mathrm{a}}$ \\ ${ }^{\mathrm{a}}$ Laboratory of Immunology, Faculty of Veterinary Medicine, University of Ghent, Merelbeke, Belgium; ${ }^{\mathrm{b}}$ Movetis NV, Turnhout, Belgium
}

Enterotoxigenic Escherichia coli (ETEC) are a major cause of dehydrating diarrhoea in children and weaned piglets living under subhygienic conditions. After colonization of the small intestine, ETEC produce heat-labile (LT) and/or heat-stable (ST) enterotoxins. Individual human ETEC strains generally produce only one type of enterotoxin, and in symptomatic patients from developing countries the heat-stable enterotoxin A (STa) producing strains seem by far the most prevalent. STa binds to and activates guanylyl cyclase C (GC-C) in the brush border of intestinal epithelium. An increase in cGMP in turn activates cGMP-dependent protein kinase II (cGKII) leading to phosphorylation of the cystic fibrosis transmembrane regulator (CFTR) driving $\mathrm{Cl}^{-}$ secretion and inhibition of $\mathrm{NaCl}$ absorption followed by net loss of water through osmotic diarrhoea. We used a small-intestinal segment perfusion model of ETEC diarrhea in pigs (Nabuurs et al. 1993, Res Vet Sci 55:108-14) in which we investigated the possibility of eliciting STa induced secretion. Five consecutive mid-jejunal segments of anaesthetized piglets were perfused for 6 hours with different concentrations of STa (150-0.62 nM) in a physiologic salt solution. Changes in intestinal net fluid absorption were measured. We concluded that the STa response was dose-dependent and that continuous perfusion with $50 \mathrm{nM}$ of STa or more was required to reduce net absorption. In all piglets the control segments showed net absorption. Fifty nanomolar of STa was sufficient to reduce net absorption compared to control segments in 10 out of 12 piglets; in 8 of them net absorption was reversed to net secretion. STa-induced responses showed relative high variation between different jejunal segments similar to the inter-segment variation seen in control animals where segments were perfused with physiologic salt solution. Results indicate that more optimization is required before this model could be used to test compounds that could interfere with the STa induced fluid secretion. 